\title{
Geochemical Prospecting
}

Investigations in the

Nyeba Lead-Zinc District

Nigeria

GEOLOGICAL SURVEY BULLETIN 1000 -B

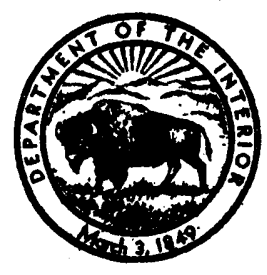





\title{
A CONTRIBUTION TO GEOCHEMICAL PROSPECTING FOR MINERALS
}

\author{
GEOGHEMIGAL PROSPEGTING IN THE NYEBA LEAD \\ ZINC DISTRIGT, NIGERIA
}

By H. E. Hawkes

\begin{abstract}
A field study of the distribution of traces of lead and zinc in weathering products, particularly residual and alluvial soils, was made in the Nyeba lead-zinc district, southern Nigeria. Similar geochemical work in temperate climates has shown that systematic sampling and trace analysis of residual soils and other weathering products hold considerable promise as a method of mineral exploration. The purpose of the present investigation was to learn whether geochemical methods of prospecting would apply equally well in a tropical environment.

The program consisted principally of detailed studies of the distribution of lead and zinc in residual and alluvial cover over known lead-zinc lodes, followed by experimental reconnaissance sampling surveys to determine the feasibility of large-scale geochemical prospecting work. A chemical kit was shipped to the field area and used for obtaining prompt analytical data to assist in guiding the sampling program.

As a result of these experiments, it is concluded that the metal content of small, near-surface samples of residual soil collected at a spacing of 100 feet would be adequate to show the location of the important lead-zinc lodes of the Nyeba district, and that the metal content of deeper samples of alluvial soil collected at a spacing not greater than the width of the lode would indicate the presence of sulfides beneath alluvial cover.
\end{abstract}

An all-African crew was trained to do all but a minor part of the routine work of sample collection and analysis.

\section{INTRODUCTION}

Even a casual glance at a map of the World's major mineral producing areas shows a conspicuously uneven geographic distribution of the sources of our various mineral commodities. It may be, however, unsafe to assume that significant mineral resources are absent in a given region simply because they have not been found there. Caution is desirable when the distribution of metal production apparently coincides with climatic zones. For example, a study of the statistical summaries of metal mining (Minerals Yearbook, 1949) shows that in 1949, 94 percent of the world's tin and 38 percent of the copper, but only 9 percent of the zinc came from mines located in the tropics. 
Possibly the climate has had some critical effect on either the formation or the discovery of economic deposits of certain metals. Tin may be as abundant in temperate latitudes as in the tropics, but may not have concentrated there in rich alluvial deposits. It may be equally true that lode deposits of zinc sulfides are just as abundant in the tropics as elsewhere, but may have escaped discovery because of the greater depth of tropical weathering. It is, perhaps, significant that, with minor exceptions, the great mines of the tropics are confined to deposits of those metals whose primary minerals are either highly resistant to weathering, such as gold and cassiterite, or oxidize to conspicuous or easily recognized secondary minerals, such as the brightly colored copper carbonates. Very few important deposits of minerals such as sphalerite that are neither resistant to weathering nor conspicuous by their oxidation products are known in the tropics. If the full potentialities of the lead and zinc resources of equatorial regions are to be realized, better methods of locating deposits of those metals must be found.

Recently, new methods of prospecting based on chemical analysis of rock, soil, vegetation, and natural water for traces of metals have been developed and applied successfully to a variety of mineral exploration problems in the United States and Canada. Such techniques, collectively known as geochemical methods of prospecting, may have applications to problems in mineral exploration peculiar to the tropics, if conditions are favorable and the operations are not too expensive.

The principal aim of the present investigation was to find out whether soil analysis could be used to locate those lead-zinc deposits that lie beneath a tropical weathering profile, and whether the cost of such a survey, if successful, could be reduced to a point where large reconnaissance exploration programs would be practical.

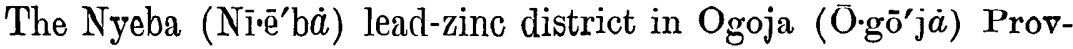
ince, southeastern Nigeria (fig. 1) was selected for these experimental studies because a private mining organization was actively developing the district, and because the Mutual Security Agency of the United States Government was currently engaged there in a geological research project which could include an experimental geochemical prospecting program. The project was financed jointly by the Mutual Security Agency, and the Nigerian Geological Survey Department. The writer served as a member of the staff of the United States Geological Survey on special loan for M. S. A. work in Nigeria.

Field work was carried out from November 1951 to January 1952. Mr. G. Jefford, chemist of the Nigerian Geological Survey Department, collaborated with the writer during the month of January 1952. R. G. Bogue, geologist of the U. S. Geological Survey in 


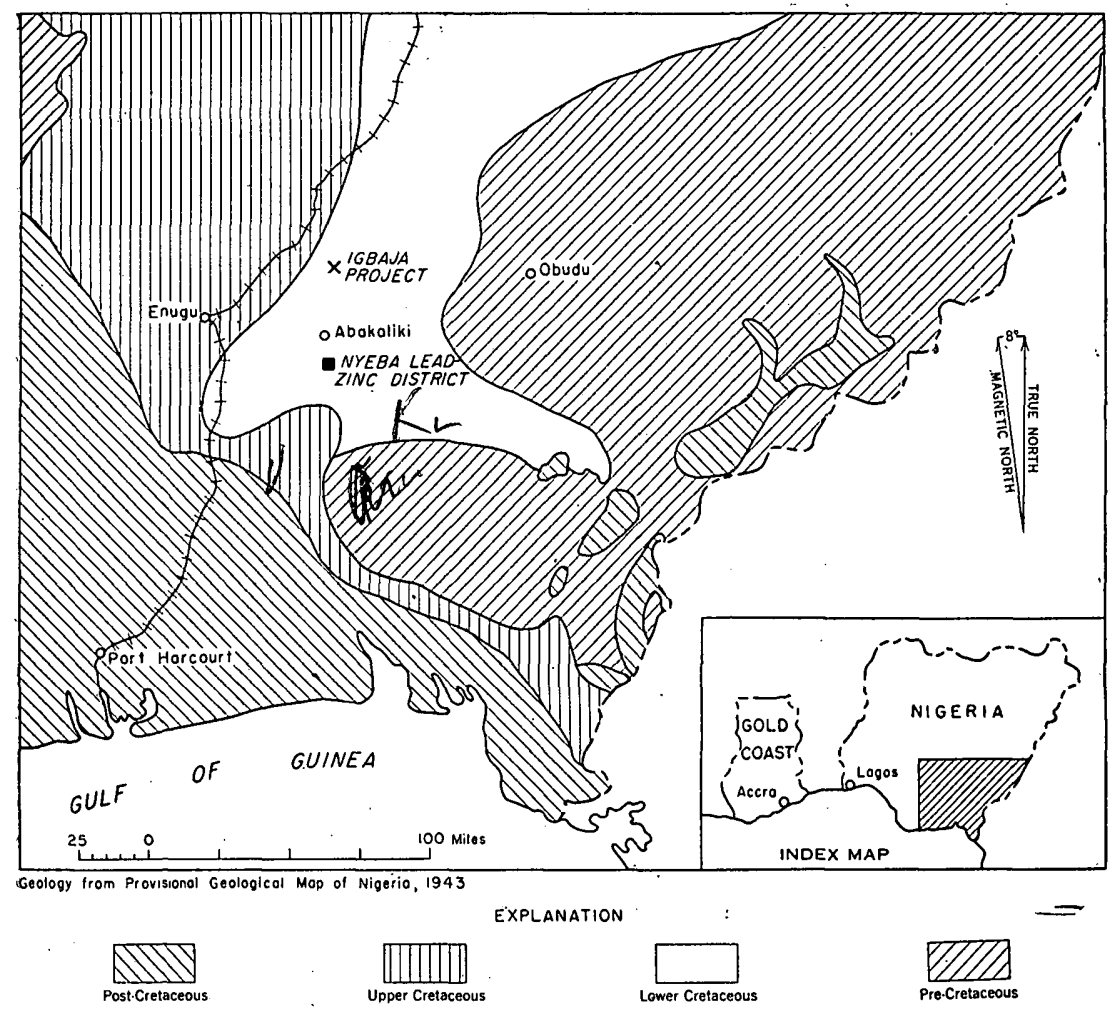

Figure 1.-Geologic Index map of southeastern Nigeria.

charge of the M. S. A. geological program in the area, took care of all arrangements for housing, transportation, and the management of the crew of African assistants. Harold Bloom of the U. S. Geological Survey assembled and packed the chemical equipment used in the field laboratory. Except as otherwise noted, the chemical analyses quoted in this report were made by $\mathrm{H}$. E. Crowe; A. P. Marranzino, and J. H. McCarthy, of the U. S. Geological Survey. The technical staff of the Nigerian Lead-Zinc Mining Company, particularly J. H. Courtright and L. M. Wilson, provided advice, services, facilities and chemical supplies without which the work would have been impossible.

\section{PRINCIPLES OF GEOCHEMICAL PROSPECTING}

Geochemical methods of prospecting for valuable minerals are based on the premise that the dispersion of ore metals in the country rock yields a characteristic distribution pattern which can be used as a guide in locating hidden ore bodies. Such distribution patterns, often referred to as geochemical "halos" or "anomalies", may encompass a very much larger volume or area of surface than the 
deposit of ore itself. Systematic surveying of unexplored ground in search of geochemical anomalies may provide a step intermediate between geologic reconnaissance and diamond drilling, which under some conditions will materially reduce the total cost of exploration.

The principles on which geochemical methods of prospecting are based are as old as prospecting itself. Since prehistoric times the systematic panning of stream sediment and residual soil for native gold or other resistant minerals has been used to find bedrock lodes. Variations in the color of soils, or peculiarities in the regetation have led prospectors to the discovery of many other important ore deposits. The application of chemical methods to the problem, however, is a relatively new feature. The first large-scale investigation of geochemical methods was done in the mid-1930's, when Soviet geologists developed methods of systematic sampling and spectrographic analysis of alluvium and soil (Sergeyev, 1941; Fersman, 1939). About the same time, workers in Sweden began large-scale programs of plant sampling and spectrochemical analysis for the purpose of mineral exploration (Rankama, 1947). Shortly after the last war, experimental work was started in the United States and Canada on a wide variety of geochemical methods of prospecting, all supported by chemical methods of trace analysis. (See Hawkes, 1948, 1950 and Harbaugh, 1953 for lists of published references.)

Recently, suitable chemical methods of trace analysis have become available, marking the turning point in the development of geochemical methods of mineral exploration. If a prospecting program based on chemical analysis of a great number of samples is to be practical, the analytical tests must be inexpensive and rapid. It is an added advantage, in that the equipment is portable and the procedures are so simple that the analytical work can be done at the base of field operations, allowing the field man to get analytical data promptly. The analytical tests developed by the U. S. Geological Survey, and now in current use in the United States and Canada (Lakin, Almond and Ward, 1952) meet most or all of these requirements.

PRIMARY ANOMALIES

Experience has shown that there are two important types of geochemical anomalies-primary and secondary. Primary anomalies include all the effects of dispersion of metals into the rocks surrounding the mineral deposit by the ore solutions. Several kinds of primary anomalies have been recognized in the course of recent work in the United States and Canada. In some districts, traces of metals are dispersed in the wall rock near the contact of the minable ore (Morris, 1952). Dispersion patterns of this kind might conveniently be referred to as "wall-rock" halos. Another type of primary halo consists of a pattern of hydrothermally dispersed metals in the rock 
overlying deposits that do not crop out at the surface (Lovering, Sokoloff and Morris, 1948; Riddell, 1950; Cooper and Huff, 1951). Primary halos are basically three dimensional features, even though they appear as two dimensional patterns on surface plans.

Little is known about the mode of occurrence of the metals in primary halos. It is generally assumed that primary dispersions of metals take the form of intricate systems of very small stringers of the common vein-forming minerals. Dispersed mineralization of this kind undoubtedly occurs in many districts, but has been overlooked because of the inconspicuous character of the introduced minerals. Such patterns can, however, be brought out by systematic chemical analysis of channel samples of rock or of the derived soil.

\section{SECONDARY ANOMALIES}

Secondary anomalies include a wide variety of patterns of metal dispersed in surficial material, that have resulted either directly or indirectly from the weathering of primary deposits. Metal that has been leached or otherwise removed from an oxidizing ore may pass through many different phases from the time it first comes under the influence of weathering agencies until it ultimately reaches the sea. Some metals tend to be held within the crystal lattice of relict primary minerals, such as cassiterite, which may be brought into the drainage-ways as heavy alluvial minerals. Other metals may be dissolved, and either reprecipitated locally in gossans and in residual soils, or carried away in solution in ground and surface waters. Some of the metal in solution may be taken up by plants and trees where it is temporarily concentrated in the living vegetable tissue. Erosion of metal-rich residual soil and gossan will carry the dispersion pattern of the metal into the stream sediments.

Secondary anomalies may be conveniently classified according to the material in which the distribution pattern is developed. A residual soil anomaly is a geochemical pattern in residual soil that shows a higher-than-normal content of metal in the rocks from which the soil was derived. Plant anomalies, sometimes called "biogeochemical" anomalies, are patterns showing a high-than-normal metal content in plant material.

When dealing with secondary dispersion, it is important to bear in mind that each element behaves differently in the course of weathering. Some elements, of which zinc is the most conspicuous example, tend to be dissolved easily and be readily transported in solution. Others, such as lead, are relatively insoluble and tend to remain in the residual soil and in the solid fraction of the stream load. Copper is intermediate between zinc and lead in its tendency to move in the weathering cycle. From the contrasting behavior of different ele- 
ments in weathering has grown the concept of "mobility" of elements; we say, for instance, that zinc is a highly mobile element whereas lead is relatively immobile. Mobility, however, is strictly a qualitative concept, representing the resultant of all the factors that tend to dissolve the element, balanced against the factors that tend to keep it insoluble or to remove it from solution. Zinc, although relatively mobile, can apparently be rendered immobile by a variety of processes that are not at all well understood. Colloidal or very fine-grained material, organic matter, biological processes, and changes in $\mathrm{pH}$ may each, under certain conditions, be effective in removing zinc from solution.

Under some conditions solution and local redeposition cause a rather special type of secondary halo, and high concentrations of metal may develop in transported cover directy above suboutcrops of sulfide ore. Presumably the metals are dissolved in the course of oxidation of the primary deposit, and migrate in solution up into the mantle of transported material where they are reprecipitated. According to Russian terminology, geochemical anomalies of this kind are "superimposed" halos, so named because the secondary geochemical pattern has been superimposed on otherwise barren material (Fersman, 1939, p. 3 of translation). In North American work, most of the known examples of superimposed halos have been observed in glacially transported material.

\section{GEOCHEMICAL THRESHOLD}

Geochemical prospecting is a process of finding areas of higher than normal metal content that indicate nearby ore deposits. This definition carries a double implication. First, the lowest content of metal that is economically significant in the material sampled must be known. This limiting value, or "threshold", should be sought by preliminary experimental work in the vicinity of known ore bodies. However, areas of higher than normal metal content can be identified and interpreted only when the normal or "background" metal content of material in unmineralized areas is known. The metal background depends on the content of metal in the various kinds of unmineralized parent rock, together with all the factors in weathering that tend to modify the content of metal in soil, vegetation, and water.

The effectiveness of a given geochemical method of prospecting depends to a large extent on the contrast between the background and the threshold value for the particular metal and the particular host material in the area under consideration. For example, 1,000 ppm (parts per million) may be the local economic threshold for lead in residual soil ; in other words, the $1,000 \mathrm{ppm}$ lead contour encloses areas deserving detailed exploration. The common range of lead background is from $20 \mathrm{ppm}$ to $50 \mathrm{ppm}$, with an average near $30 \mathrm{ppm}$. Here 
the contrast is $1,000 \mathrm{ppm}$ against $30 \mathrm{ppm}$, or 30 to 1 , which is a very satisfactory ratio for a geochemical reconnaissance method. For zinc, the threshold may be $200 \mathrm{ppm}$ against $50 \mathrm{ppm}$ background, giving a contrast of 4 to 1 . Here the less satisfactory contrast for zinc may be offset by other factors, such as the greater simplicity of the analytical test for zinc and possibly the broader areal extent of the zinc anomalies.

\section{CONTAIMINATION}

Contamination of surficial material as a result of human activity presents an ever-present hazard when variations in minute amounts of metal may be significant. The most common sources of contamination are old surface workings, where fresh or oxidized ore has been thrown out and scattered over the surface. A very small increment of oxidized zinc ore may raise the zinc content of residual soil well above the economic threshold.

When deposits are opened by either opencast or underground work, the primary minerals are subject to vastly accelerated oxidation and solution. This may be disastrous to geochemical studies of water, as the metal content of ground and surface water in the vicinity of old mines is probably tens or even hundreds of times greater than before the deposit was developed. Thus the small increment from an undiscovered deposit may be completely masked by the excessive contribution of metal to the drainage water by old prospects.

Stream sediment may become useless as a result of contamination from mine dumps and mill tailings. Smelter fumes and wind-blown dust from mill tailings have been known to contaminate surface soils within two or more miles of the smelter stack. Needless to say, the geochemical prospector must be constantly on guard against the possibility of contamination.

\section{NEED FOR PRELIMINARY ORIENTATION STUDIES}

Not enough geochemical prospecting work has been done to justify a forecast in a new area as to whether primary anomalies may be expected, which soil horizon will yield the most significant soil samples, what the optimum spacing will be for soil or vegetation samples, which types of vegetation will provide the most significant samples, whether soil or vegetation will give the best results, whether water or sediment sampling will be useful, and what will be the disturbing effect of contamination from human activity. It is virtually mandatory that at the beginning of any new field project, experiments be carried out to determine the answers to those questions pertinent to the local geochemical problem: Once these questions have been answered, then and only then can a routine geochemical exploration work program be intelligently planned. 


\section{GEOLOGY}

The Nyeba district lies near the southern end of the Nigerian leadzinc belt, about 10 miles south of Abakaliki ( $\bar{A}^{\prime}$ bá.kă'li.kè $)$, and 50

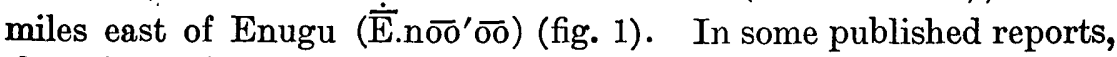
the mines of the Nyeba district have been included as part of the Abakaliki district, which comprises a considerably larger area covering the small prospects near Abakaliki as well as the principal deposits centering about the settlement of Nyeba.

\section{GENERAL}

The geological setting of the Nigerian lead-zinc belt has been summarized recently by Mackay (1950), Webb and Millman (1950, 1951), Bogue and Reynolds ${ }^{1}$, and Farrington (1952). The following summary is quoted from Webb and Millman (1951):

(a) Sedimentary rocks. A belt of dominantly sedimentary rocks, probably of Lower Cretaceous age, trends northeast for about 400 miles from near Enugu in the Eastern Provinces of Nigeria. The stratigraphy and structure of the belt are imperfectly known (Tattam, 1943). Shales and siltstones are the principal sedimentary rocks, and sandstones are common in the north of the region. Thin intercalated limestones and calcareous horizons in the argillaceous rocks are not unusual. The sediments are folded into gently pitching anticlines or elongated domes, generally along predominantly east-west lines; dips rarely exceed $30^{\circ}$. In the Ameka-Ameri ( $\dot{A}^{\prime} m \check{c} . k \dot{a}, \check{A} . m e ̨$ ré) area (herein referred to as the Nyeba district) NE-SW anticlinical folding constitutes the important structural feature (Tattam, 1930 ; fig. 4). Cross (ac) joints are well developed and oblique shear joints less so.

(b) Igneous rocks. The sediments are intruded by relatively small dykes, necks and stocks of syenitic to doleritic igneous rocks (Tattam, 1943, p. 41). Volcanic rocks of more recent age occur in various parts of the Cretaceous belt. Occasionally lead-zinc veins cut basic igneous intrusions and at Abakaliki the mineralization occurs in volcanic rocks of andesitic type.

\section{MINERAL DEPOSITS}

The following description of the ore deposits of the Nyeba district is quoted from Bogue and Reynolds. ${ }^{2}$ The location of the various deposits is shown on figure 2.

\section{STRUCTURE}

The known ore deposits in the district, those at Abakaliki and in the vicinity of Nyeba, are on the north-south and northwest-southeast fault zones. Movement on these faults has not occurred on a single fault plane but along a number of parallel, closely spaced fractures, forming a fault zone of considerable width. The mineralization is not confined to any single fracture in the fault zone. The deposits are composed of a number of individual ore bodies within the fault zones and have an echelon pattern both vertically and horizontally.

\footnotetext{
${ }^{1}$ Bogue, R. G., and Reynolds, R. R., 1951. Preliminary report on the lead-zinc deposits of the Abakaliki district, Nigeria: U. S. Geol. Survey unpublished report, $19 \mathrm{p}$.

a Bogue, R. G., and Reynolds, R. R., op. cit.
} 


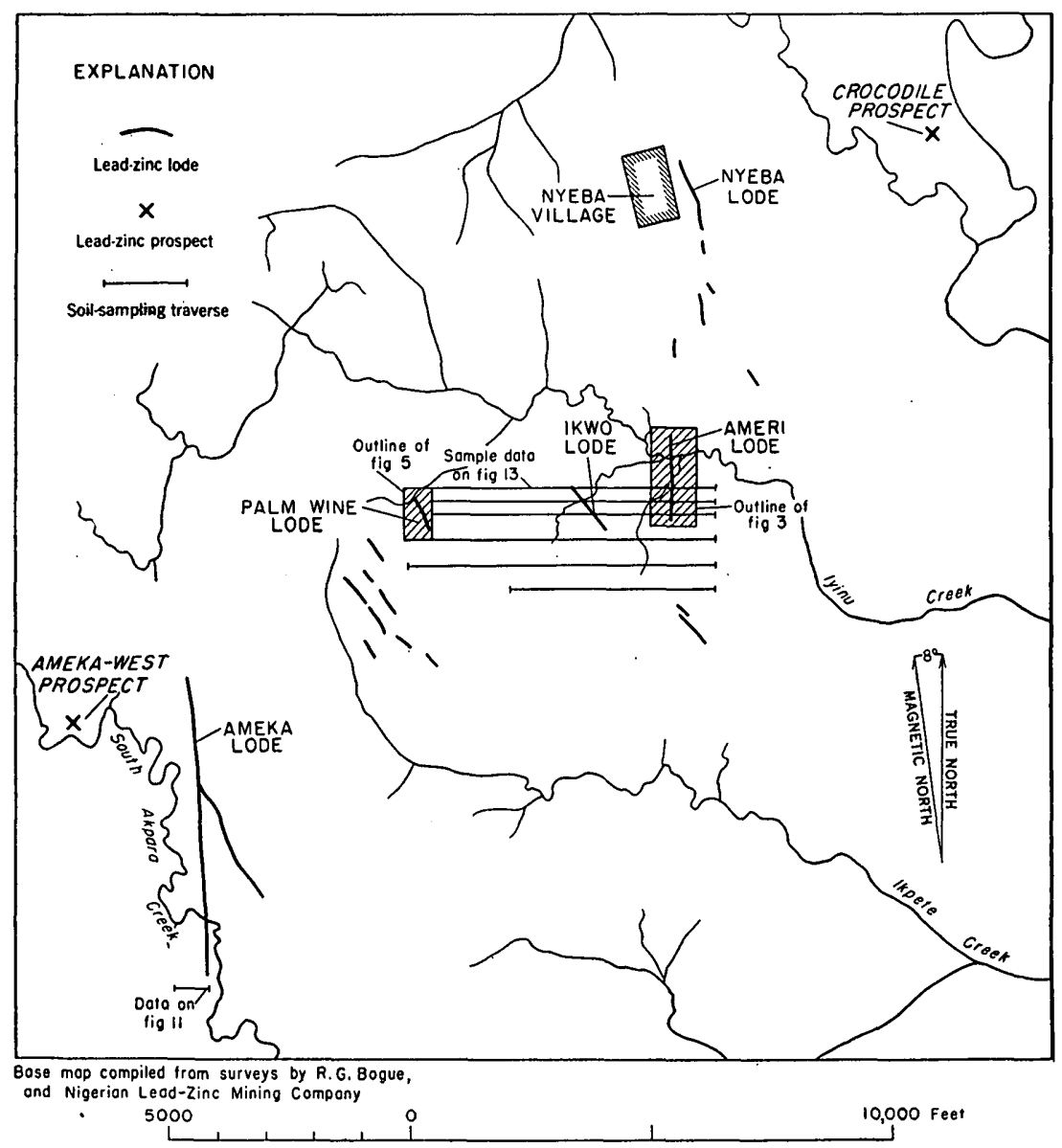

Figurn 2.-Index map of Nyeba lead-zinc district.

Quartz veins which have been emplaced in the fault zones at Ameka and, to a lesser extent at Nyeba, have been resistant to erosion and have given local topographic expression to the outcrops. However, where there is no quartz in the veins, there is no topographic expression of the orebodies.

The individual ore bodies are apparently lenticular in form. The exact shape of most are not known but may extend several hundred feet horizontally and vertically and up to 40 feet in width. There is not enough evidence at the present time to determine the pitch of the ore lenses, but there is a suggestion of a general pitch of the longitudinal axes to the south at about $30^{\circ}$ to $50^{\circ}$.

The mineralization is largely confined to the fault zones and there is almost no leakage of the ore minerals into the unbrecciated shales on either side of the faults. However, small veins of dolomite and siderite occur in the wall rocks. The introduced minerals have replaced the brecciated shales within the fault zones. There is no evidence of fissure filling in the deposits except marcasite, which was introduced late in the mineralization sequence.

Wall rock alteration is not apparent in the shales more than a foot or two from the ore bodies. In no place were the shales observed to be intensely altered, but small amounts of fine-grained mica, probably hydro-muscovite, and clay 
have been found. Hydromuscovite, clay and chlorite are often observed in the brecciated shales in the fault zones, especially in the vicinity of the mineralization. There has been some silicification of the wall rocks; however, it is not widespread and is erratically distributed throughout the deposits. It is believed that this silicification was caused by quartz which was introduced late in the sequence of mineralization and caused some silicification of the wall rock and formed veins in the surrounding area. These quartz veins are widespread throughout the district and usually occupy northwest-southeast fractures, though a small percentage are in fractures of random orientation.

\section{MINERALOGY}

The mineralogy of the ore deposits is relatively simple and consists of but few primary minerals. The minerals arranged in the order of their paragenesis are as follows :

Dolomite. Cream or pale pink in colour and occurs in small veins throughout, and adjacent to, the mineralized area. It is most abundant in the brecciated shale of the fault zones and small veinlets are often present in the wall rock.

Quartz. This is an early generation of quartz, which was introduced during and shortly after the dolomite. It is usually dense, finely crystalline, milky white, and occurs usually in small veins but in places has been found in veins several feet in width. There is evidence that some of this quartz may have been introduced about the same time as the siderite. However, in most places it is definitely later than the siderite.

Siderite. Usually light brown or grayish buff in colour on freshly broken surfaces but changes to a reddish brown when exposed. Most of the siderite is crystalline with crystal faces up to several inches in length, but some is dense and has a granular appearance. There is a late generation of siderite which is usually a darker shade of brown.

Chalcopyrite. Widely distributed throughout the deposits in minor quantities. It usually occurs as small rounded grains in the siderite but occasional masses several inches in diameter have been found.

Sphalerite. The colour varies from light to dark brown and is generally well crystallized. Crystal faces up to 6 inches in diameter are not uncommon, but well-formed, euhedral crystals are quite rare.

Galena. There are two types of galena present, the early, which has a cubic form and a very minor amount of the late which has an octahedral crystal form. The early galena is usually well crystallized but occasional masses of fine textured, granular galena are found. Late quartz, calcite, and barite were introduced after the cubic galena. These minerals are usually in small veinlets and erratically distributed throughout the deposits. Small amounts of late chalcopyrite associated with late siderite and some pyrite have been found. There is not enough evidence to determine the exact sequence of the introduction of these minerals except that it is known that all are later than the first galena and earlier than the marcasite.

Marcasite. This mineral is locally abundant in certain of the ore lenses at Ameka and in lesser amounts in the other deposits. It usually is in botryoidal crusts but sometimes is found in masses several feet thick.

Galena. Small crystals of octahedral galena have been found coating the marcasite. This type is probably the result of solution and redeposition of the earlier galena.

There are a number of secondary minerals in the oxidized portions of the ore outcrops. The outcrops were mined down to the water table at Ameka and Nyeba about 20 years ago so that most of the secondary minerals are found 
on the old dumps although occasionally they may be seen in place. The secondary minerals are listed below :

Limonite and related iron oxides

Cerussite

Calamine

Smithsonite

Clay-mostly kaolinite, some allophane(?)

Chalcedony

Malachite

Azurite

Pyromorphite

Anglesite

Calcite

\section{SURFICIAL FEATURES}

In southern Nigeria, as in most tropical areas, geologic mapping and mineral exploration are severely handicapped by lack of natural exposures of the unweathered bedrock. Conclusions as to lithology, structure, and primary mineralization must be made by piecing together the fragmentary evidence obtained from studies either of weathered rock or of residual soil. Therefore, the effectiveness of geologic work depends in no small measure on the competence of the observer to interpret the effects of the many natural and human agencies that have contributed their share to the surficial history of the region.

In view of the importance of surficial factors in mineral exploration in the tropics, it is regrettable that their effects are so little understood, either generally or locally. The following remarks, therefore, must be kept largely on an empirical and descriptive level. What tentative conclusions are drawn are based on very incomplete evidence.

\section{LAND FORMS}

The topography in the general vicinity of the Nyeba district is nearly level or only slightly undulating. The general elevation is slightly less than 300 feet above sea level, although scattered hills of relatively resistant rocks stand a hundred feet or more above the level of the plain. Near the watersheds, the stream drainage follows broad swales in the gently rolling surface. Larger streams and rivers flow in sharply incised channels as much as 30 feet deep cutting the original, almost featureless surface. The present active downcutting of the larger streams undoubtedly results from a relatively recent regional uplift. ${ }^{3}$ Perennial springs are common throughout the district. Many of these springs have been enlarged and excavated by the natives as reservoirs or "juju $(j \overline{00}$ ' $j \overline{00})$ pools" to provide a source of water throughout the dry season.

\footnotetext{
${ }^{3}$ Bogue, R. G., and Reynolds, R. R., op. cit.
} 


\section{CLIMATE}

The average annual rainfall in the Nyeba district is 60 to 80 inches. Virtually all falls during the rainy season, which lasts from May to October. Much of the precipitation comes in torrential showers, with resulting high runoff and erosive action. From November through February the tropical continental air from the Sahara desert periodically moves southward, displaces the tropical maritime air of the Gulf of Guinea, and brings with it high winds, dust, and extremely arid conditions. The dry winds of the winter months are locally known as the "harmattan" (här'mă·tăn'). During the harmattan period, the exposed soil dries out, and water disappears from all the smaller springs and drainage channels. Water remains throughout the year in many of the juju pools, although at the end of the dry season it may consist only of a stagnant and putrid residue. The temperature is uniformly warm except during the harmattan period, when night temperatures may fall as low as $50^{\circ} \mathrm{F}$. Freezing weather is unknown in southern Nigeria.

\section{WEATHERING}

Two sharply contrasting weathering profiles were observed in the Nyeba district. One type, occurring in relatively well-drained areas, is characterized by the accumulation of oxides of iron, a process commonly referred to as "lateritic". weathering. The other type is confined to poorly drained and swampy areas and leads to the formation of a heary clay.

\section{WELL-DRAINED AREAS}

The weathering profile in the relatively well-drained areas of the Nyeba district is characterized by a tendency for silica to be leached and for.iron to be relatively enriched (see table 5). The content of organic matter is apparently very low, except for surface litter and live rootlets. Following is the typical profile, reading downward from the surface:

a. Surface organic litter.

b. Fragmental zone. This is a zone, rarely more than 18 inches thick, consisting of fragments of weathered shale mixed with varying proportions of bead-sized nodules or pellets of aluminous and ferruginous material. This zone constitutes the "soil" that is periodically turned over and mixed during the course of native cultivation. Thus it is in reality hardly a part of the natural weathering profile, as much of the original layer undoubtedly has been removed by erosion, and also has been admixed with fragments broken off from the underlying weathering shale or laterite. Virtually all the drained terrain in the district is now being or has been subjected to this treatment, and no natural, undisturbed profile could be seen. In its present state, the 
fragmiental zone is pervious and notably low in its content of claysized particles.

c. Laterite. In perhaps 10 to 20 percent of the drained parts of the district, the fragmental zone is underlain by a two- to four-foot layer of consolidated buff to red-brown material. When freshly exposed, this material can be chopped and shaped, much like stiff clay. Upon exposure to the air, it becomes hard and stony. It typically contains through-going, usually subvertical pencil-sized channels, which resemble worm-holes. These channels may be either empty or filled with earthy, claylike material. Many of the channels are now occupied by live rootlets. The term "laterite" has been locally applied to this zone, but because of the confusion regarding the exact definition of a laterite (see du Preez, 1948), any such classification should be applied with caution.

d. Weathered bedrock. The fragmental zone, or the laterite if present, is directly underlain by weathered bedrock, either shale or siltstone. The boundary is commonly very sharp. The weathered bedrock is essentially in place, except for a certain amount of slumping due to leaching or slope creep. It is commonly buff colored, and relatively soft and crumbly. Through a zone extending from 5 to perhaps 50 feet below the surface of bedrock, the buff coloration grades irregularly into gray, and the consistency becomes harder and more compact.

\section{POORLY DRAINED AREAS}

During the rainy months, areas where the topographic gradient is sufficiently low are covered by standing water for long periods of time. Such areas occur in many of the broad-upland stream channels, and in level areas both near watersheds and in the larger valley bottoms. During the dry season, the standing water drains away, but the surface soil immediately below the vegetative cover remains moist. In such areas, the weathering processes apparently favor formation of clay rather than of iron and aluminum oxides. The poorly drained areas of the district are in general not arable and undisturbed weathering profiles remain that could be studied. The boundaries between well-drained areas of lateritic weathering and poorly drained areas where weathering leads to the formation of clay are relatively sharp, with a transitional zone of rarely more than a few tens of feet. Following is a typical profile, as observed in a trench 11 feet deep and 100 feet long excavated in a swamp area near the Crocodile prospect (fig. 2).

a. Organic zone. As much as 12 inches. The roots of the swamp flora, mainly grasses and reeds, are embedded in a dark-gray organic zone.

$293432-55-3$ 
b. Gray clay zone. 12 to 36 inches. The organic zone grades downward with decreasing amounts of organic matter into the underlying clay zone. The color grades downward from dark gray to light blue gray.

c. Mottled clay zone, below 36 inches. The zone below the gray clay is a mottled brick-red and blue-gray clay. The proportion of red coloration to gray increases somewhat with depth. Where live rootlets penetrate the mottled zone, they are surrounded by 2 -inch zones of even-hued blue-gray clay, which suggests that in the vicinity of the rootlets the iron oxide of any red clay present had been reduced. Rootlets were observed at depths as much as 11 feet below the surface. The clay, although moist throughout, is very impervious to moving water. In a profile of residual clay exposed on the walls of a deeply incised modern drainage channel near the Crocodile prospect, the indistinct traces of the original bedding of the parent rock could be seen.

d. Weathered bedrock. The mottled clay.grades downward through a transitional zone of a foot or two into weathered bedrock, where the original sedimentary structures of the shale or siltstone are easily seen. Bedrock was found at a depth of 22 feet in a shaft in the bottom of the trench. In poorly drained terrains, weathering processes acting on parent materials of different origins lead to end products that are extremely difficult to distinguish. Thus from a cursory examination of near-surface material, it is virtually impossible to tell whether the parent material was indigenous shale bedrock or a deposit of transported alluvium. This problem will be discussed later in connection with the experiments in the Ameri swamp.

\section{NATURAL VEGETATION}

Webb and Millman (1951) state that the Nyeba district is

well within the northern climatic limits of the forest zone, but owing to degradation by native agriculture and bush fires the vegetation is now mostly derived savannah, the main forest boundary lying a few miles to the south.

According to the most reliable local information, the original forest was cleared several hundred years ago by natives who were driven out of their original farmlands in the north by hostile tribes. At the present time, remnants of the original hardwood forest may be seen only in scattered patches, principally along the larger streams and rivers in the bottomlands which were unfavorable for agriculture.

\section{AGRICULTURE AND SOIL EROSION}

The indigenous agriculture practised by the local natives is a yam culture. Yams are root vegetables that will rot before maturing if the enclosing soil is saturated with water over any substantial part of the growing season. It has become the local practice, therefore, 
to plant the yams in conical hills of soil commonly 2 to 3 feet high. It is difficult to imagine an agricultural practice that would do more to promote soil erosion than the building of conical piles of this kind. Not only is fresh soil periodically exposed to the torrential tropical rains, but unobstructed channelways are opened up for the removal of eroded material by the runoff water. As a result, any true soil in the agricultural sense has long since been removed, and the fragmental surface material remaining is hardly more than the coarest fraction of the original soil that was not as readily washed away, plus fragments of weathered shale dislodged from the immediately underlying bedrock. It is conceivable that most of the soil erosion took place as an almost catastrophic event immediately after the clearing of the forest, some four hundred years ago. The thickness of material that has been eroded is probably more than 5 feet. Further field investigations aimed specifically at unraveling the recent history of the Nyeba district would undoubtedly provide answers for many of these questions.

The lack of a true soil, and the present negligible thickness of the layer of fragmental material overlying weathered bedrock, are of extreme importance in mineral exploration. Diagnostic fragments derived from the oxidation zone of sulfide lodes are broken off and mixed with the surface fragmental horizon in the course of building yam heaps. Native prospectors, sent out by the different previous European managements of the mines, have systematically searched the cultivated fields for fragments of vein quartz, limonitic gossan, and "lead float" or crystals of galena coated with gray lead sulfate. It is very unlikely that any large lode deposit in the well-drained areas of the district is undiscovered. This conclusion applies, however, only to the well-drained terrain, where the overburden is shallow; prospecting the clay-covered swamps is quite another problem. In the poorly drained areas covered by clay where no surface expression of lode sulfides could be expected, ore bodies of substantial size could easily have been overlooked.

\section{NATIVE IMINING}

Although apparently no written records or native folklore survive of any iron smelting activity in southern Nigeria, iron making must have been an active industry there at one time in the past. This is attested by the widespread distribution of small fragments of slag in the surface material, and by large mounds consisting of many tons of slag in areas twenty to forty miles north of the Nyeba district. The remaining evidence for this activity is extremely fragmentary, although careful studies would almost certainly provide the answers.

Samples of slag from widely separated localities, both within the 
Nyeba district and elsewhere, were collected by the writer and analyzed for lead and zinc, with the following results:

TABLE 1.-Lead and zinc content of slag samples

\begin{tabular}{|c|c|c|}
\hline \multirow{2}{*}{ Locality } & \multicolumn{2}{|c|}{ Parts per million } \\
\hline & Lead & Zinc \\
\hline $\begin{array}{l}\begin{array}{l}4 \text { miles south of Nyeba } \\
\text { Ameka West prospect } \\
\text { Palm Wine lode } \\
\text { 5 miles northeast of Abakaliki } \\
\text { Do } \\
\text { Do }\end{array} \\
\begin{array}{l}\text { 14 miles north of Abakaliki } \\
15\end{array} \text { miles north of Abakaliki } \\
\text { Igbaja } 1 \text { prospect. }\end{array}$ & $\begin{array}{r}300 \\
4,000 \\
75 \\
130 \\
50 \\
25 \\
400 \\
50 \\
25\end{array}$ & $\begin{array}{l}150 \\
600 \\
300 \\
200 \\
100 \\
100 \\
350 \\
100 \\
100\end{array}$ \\
\hline
\end{tabular}

$1 \mathrm{Ig} \cdot \mathrm{bő} \mathrm{j} j \mathrm{i}$.

Guillemain (1910) reports that in the Cameroons, several hundred miles east of the Nyeba district, the natives used iron-rich laterite for iron ore. However, the high lead and zinc content of some of the slag samples reported in table 1 suggest that in part, at least, the raw material for the iron industry within 30 miles of Nyeba was metal-rich limonitic gossan.

The native tribes of southern Nigeria have also mined many of the oxidized outcrops of the lead-zinc lodes for crystals of galena, which were crushed and used for cosmetics. Only the larger cubic crystals were saved, as the fine-grained galena, for some reason, had no commercial value in the native markets. This activity has continued up to relatively recent times. T. G. H. Cotsworth, senior inspector of mines at Enugu, has learned from discussion with local natives that it was common practice for members of each tribe to forage outside of their own tribal boundaries for oxidized ore containing relict galena crystals. Blocks of unsorted gossan were gathered wherever they could be found and brought in baskets as much as 6 miles back to the home village for sorting. Spillage in transit and undesirable galena discarded at the sorting pile could leave a pattern of galena float that would be most distracting to the exploration geologist.

A problem of this kind apparently was encountered at the Crocodile prospect in the Nyeba district. One of the exploration trenches in this area uncovered remains of a pit about three feet deep, now filled with rubble consisting mainly of somewhat discolored fragments of weathered shale together with a few fragments of charcoal and pottery. A composited sample of the surface fragmental material collected within 30 feet of this pit contained $1,000 \mathrm{ppm}$ lead. The average lead content of nine soil samples taken at 50 -foot intervals along a traverse across the area with $200 \mathrm{ppm}$, or about four times the lead content of normal soil. Within the same area, African scouts employed by the mining company had found scattered small fragments of galena in the 
surface material. Thorough trenching of the area failed to find any evidence whatever of mineralization. The pit may indicate the existence here of a native village at some time in the past, where, conceivably, the inhabitants sorted gossan brought from the Nyeba deposit one mile to the west.

A similar problem may exist at the Ameka West prospect, also in the Nyeba district, where abundant fragments of galena had been found at the surface, but where extensive trenching also failed to find any bedrock mineralization.

For the purposes of the modern prospector, the significant conclusions to be drawn from these observations are that the presence of lead float, and geochemical soil anomalies in lead are not necessarily indicative of bedrock sulfides in the immediate vicinity.

\section{PREVIOUS GEOCHEMICAL PROSPECTING WORK}

The first geochemical prospecting work in the Abakaliki district was carried out by R. O. Roberts (1953) in 1948 and 1949 in conjunction with an experimental geophysical survey. Roberts made determinations of lead and zinc on a total of 102 samples of soil collected at intervals varying from 20 to 500 feet along three transverse lines. Although the resulting data, particularly for the distribution of lead, showed considerable promise, the project was discontinued before any very definite conclusions could be drawn.

At about the same time, J. S. Webb and A. P. Millman of the Royal School of Mines conducted experimental geochemical water and vegetation surveys in the Nyeba district. . This work has been described in full in their published reports (Webb and Millman, 1950, 1951), and will be reviewed and discussed later in connection with the results of the present investigation.

R. J. Lacy and L. M. Wilson of the geophysical department of the American Smelting \& Refining Co., one of the parent companies of the Nigerian Lead-Zinc Mining Co., set up a geochemical prospecting laboratory at their field headquarters in Nyeba. They assembled the necessary reagents and equipment, and did some preliminary soil and water surveys. Officials of the mining company kindly made available for the writer's use the supplies and equipment from this laboratory.

\section{ANALYTICAL PROCEDURES}

For maximum economy and general effectiveness, the analytical methods used in geochemical prospecting work should be not only sensitive, but also both rapid and simple. Because of the usual wide range of metal content encountered in most problems in geochemical prospecting, high accuracy is not required. To meet this need the Geological Survey has developed a series of rapid and simple colorimetric tests suited to the practical requirements of geochemical pros- 
pecting work. Tests for lead and zinc in soils were evolved from the standard colorimetric methods (Sandell, 1950) by elimination of many of the precautionary but tedious steps needed for highly accurate work.

The procedures used for the Nigerian project embody some modifications over those previously described in the literature (Lakin, Stevens and Almond, 1949; Almond and Morris, 1951; Lakin, Almond and Ward, 1952). The following pages give the analytical procedures as they were actually used on the samples from Nigeria and are essentially the same as those subsequently described by Bloom and Crowe. ${ }^{6}$

A selected group of samples were analyzed in the Denver laboratory for copper, cobalt, nickel, silver, arsenic, and antimony in addition to lead and zinc. The cobalt and arsenic procedures used for this work have been described by Almond (1953), ${ }^{4}$ the antimony procedure by Ward and Lakin, ${ }^{5}$ and the others by Lakin, Almond, and Ward (1952).

\section{EQUIPIENT FOR FIELD LABORATORY}

In the early stages of any experimental geochemical prospecting project, the analytical data should be available within a day or two after the samples are collected, to assist in the daily decisions needed in feeling out the most effective geochemical approach to the local exploration problem. Once the general approach has been, selected on the basis of such preliminary experimental work, then fairly large sampling programs may be laid out without the necessity for prompt analytical reports.

Reagents shipped by air to the project area included one bottle thymol blue solution, $150 \mathrm{~g}$ purified potassium cyanide, $300 \mathrm{~g}$ ammonium citrate, $200 \mathrm{~g}$ sodium thiosulfate, $400 \mathrm{~g}$ sodium acetate, 113 g hydroxylamine hydrochloride, and 24 vials each containing $0.01 \mathrm{~g}$ dithizone. Inasmuch as international air freight regulations prohibit the shipment of any corrosive liquids, itwas necessary to borrow nitric acid, acetic acid, ammonium hydroxide, and carbon tetrachloride from the local laboratory at Nyeba.

- Also, in the same year, Almond, Hy, 1953, A field method for the determination of arsenic in soils, in U. S. Geological Survey open-fle report, No. 208, Additional fleld methods used in geochemical methods used in geochemical prospecting by the $U$. $\mathrm{S}$. Geological Survey, p: 8-12.

'Ward, F. N., and Lakin, H. W., 1953, Determination of microgram quantities of antimony in soils and rocks in U. S. Geological Survey open-flle report, No. 208, Additional field methods used in geochemical prospecting by the $U$. $\mathbf{S}$. Geological Survey. p. 3-7.

- Bloom, Harold, and Crowe, H. E., 1953, Determination of readiy soluble copper, zinc, and lead in soils and rocks : nitric acid digestion, in U. S. Geol. Survey open-flle report, No. 208, Additional field methods used in geochemical prospecting by the $U$. S. Geological Survey, p. 16-24. 
The analytical field kit included the following apparatus :

1 Stainless-steel sieve, 80 -mesh

1 Stainless-steel spatula

1 Camel's-hair brush

$11 \frac{1}{2}$-inch paintbrush

1 Lucite spoon, consisting of a lucite bar drilled with cavity suffcient to hold $0.1 \mathrm{~g}$ of soil

100 Pyrex culture tubes, $16 \times 150 \mathrm{~mm}$, marked at $10 \mathrm{ml}$

2 Glass-marking pencils

50 Boiling-tubes, for prevention of bumping during digestion of sample. These are 9-inch sections of glass tubing, inside diameter $2 \mathrm{~mm}$, on which the bore has been sealed off about one inch from bottom. This may be done by softening the glass over a flame, and crimping with a strong pair of crucible tongs.

2 Steel fusion racks for test tubes

2 Coleman petrol stoves

2 Test tube racks for 40 test tubes each

2 Test tube brushes

2 Test tube clamps

1 100-ml Glass-stoppered pyrex graduate

2 50-ml Glass-stoppered pyrex graduates

625-ml Glass-stoppered pyrex graduates

3 125-ml Pyrex separatory-funnels

1 Separatory-funnel rack

10 Culture tubes with plastic screw caps for standards

2 Culture tube racks for comparison of standards

3 500-ml Pyrex reagent-bottles

1 Polyethylene wash-bottle

6 Volumetric pipettes: $2,2-\mathrm{ml} ; 2,3-\mathrm{ml} ; 2,5-\mathrm{ml}$

10 Graduated pipettes : $2,0.5-\mathrm{ml} ; 3,1-\mathrm{ml} ; 2,5-\mathrm{ml} ; 3,10-\mathrm{ml}$

1 Porcelain pipette-holder

4 Dropping-bottles

2 Sets of $\mathrm{pH}$ papers : 1-7 and 7-14

2 Demineralizer cartridges

Miscellaneous: stirring-rods, litmus paper, gummed labels, files, ear syringes, corks, stopcock grease, paper tissue, towels.

The following equipment needed for the field laboratory was borrowed from the mine laboratory at Nyeba:

1 Pyrex still, for distillation of carbon tetrachloride.

1 Analytical balance for weighing reagents. This is not necessary if adequate quantities of prepared regents in previously weighed batches are prepared in the supporting laboratory.

1 Dispenser, for dithizone solution, consisting of a 1-pint thermos jug fitted with a two-hole rubber stopper, an atomizer bulb, and glass nipple and tubing. This device, developed by L. M. Wilson of the 
American Smelting and Refining Co., keeps the solution both dark and cool and provides an easily controlled discharge. Direct pipetting of dithizone solution should be avoided because of the toxic properties of carbon tetrachloride.

1 Kerosene refrigerator for storing dithizone stock solution.

\section{DETERIMINATION OF LEAD AND ZINC IN SOILS}

The following rapid procedures for estimating traces of lead and zinc in soils were used both in the field and in the laboratory of the U. S. Geological Survey. For a full discussion of colorimetric methods of analysis, the reader is referred to the publications of Lakin, Almond, and Ward (1952) and Sandell (1950).

\section{PREPaRATion of REAGents}

Water. Pass distilled water from a standard laboratory still through a resin demineralizer. All water used for the following reagent solutions were prepared in this way.

Nitric acid, 1:3. Dilute one part analytical-grade nitric acid with three parts water; the nitric acid borrowed from the mine laboratory was tested and found to be essentially free of lead and zinc.

Ammonium citrate, $10 \%$. Dissolve $100 \mathrm{~g}$ commercial ammonium citrate in $900 \mathrm{ml}$ water; if contaminated, this solution may be scrubbed by shaking, with dithizone solution. To scrub, add approximately 15 $\mathrm{ml}$ of 0.1 per cent dithizone solution to 1 liter of the ammonium citrate solution, and shake for about 1 minute. If the final color of the dithizone solution is not green, separate the $\mathrm{CCl}_{4}$ layer, and repeat until the final dithizone product is green. Then remove dithizone from the aqueous phase by shaking for a half minute with successive $15 \mathrm{ml}$ portions of $\mathrm{CCl}_{4}$ until the final $\mathrm{CCl}_{4}$ solution is colorless.

Ammonium hydroxide, $1 \mathrm{~N}$. Dilute $70 \mathrm{ml}$ concentrated ammonia to 1 liter. Commercial ammonia, although it may be seriously contaminated with zinc, is commonly sufficiently free of lead to be suitable for use in the lead procedure.

Potassium cyanide: For 30 percent solution, dissolve $300 \mathrm{~g}$ metalfree $\mathrm{KCN}$ in $700 \mathrm{ml}$ water. For 0.1 percent solution, dilute one part 30 percent solution with 300 parts water.

Thymol blue indicator, 0.4 percent. Dissolve $0.04 \mathrm{~g}$ of the sodium salt in $100 \mathrm{ml}$ of water.

Buffer for zinc. Dissolve $300 \mathrm{~g}$ sodium acetate $\left(\mathrm{NaC}_{2} \mathrm{H}_{8} \mathrm{O}_{2} .3 \mathrm{H}_{2} \mathrm{O}\right)$ and $125 \mathrm{~g}$ sodium thiosulfate $\left(\mathrm{Na}_{2} \mathrm{~S}_{2} \mathrm{O}_{3} .5 \mathrm{H}_{2} \mathrm{O}\right)$ in water; add $60 \mathrm{ml}$ of glacial acetic acid; dilute to 2 liters; if contaminated, this solution may be scrubbed by shaking with dithizone solution.

Dithizone solution. For 0.01 percent stock solution, dissolve $0.01 \mathrm{~g}$ in $100 \mathrm{ml}$ carbon tetrachloride. For 0.001 percent working solution, dissolve 1 part stock solution in 9 parts carbon tetrachloride. 


\section{SAMPLE DIGESTION}

Measure $0.1 \mathrm{~g}$ minus 80-mesh soil sample in lucite spoon and place in dry test tube. Add $2 \mathrm{ml}$ nitric acid. Insert boiling-tube and boil for one-half hour, adding water from time to time to maintain level of liquid. Remove boiling-tube, dilute to $10 \mathrm{ml}$ with water, mix, and allow to settle.

\section{ESTIMATION OF LEAD}

With pipette, transfer aliquot of solution from test tube to separatory funnel containing $4 \mathrm{ml}$ ammonium citrate solution. Add 2 drops of thymol blue and sufficient $\mathrm{NH}_{4} \mathrm{OH}$ to turn the solution distinctly yellow. Add about $0.1 \mathrm{~g}$. of hydroxylamine hydrochloride if difficulties with oxidation of dithizone are anticipated. Add 10 percent KCN solution until thymol blue indicator turns toward blue. Add $5 \mathrm{ml}$ of 0.001 percent dithizone solution and shake gently for 10 seconds. Drain $\mathrm{CCl}_{4}$ layer into cylinder containing $10 \mathrm{ml}$ of 0.1 percent $\mathrm{KCN}$ solution and shake. Compare color of $\mathrm{CCl}_{4}$ layer with 1-, 2-, and 3-microgram lead standards similarly prepared.

\section{ESTIMATION OF ZINC}

With pipette, transfer aliquot of solution from test tube to a $25 \mathrm{ml}$. stoppered graduate containing $8 \mathrm{ml}$. of zinc buffer solution. Add 5 $\mathrm{ml}$ of 0.001 percent dithizone solution and shake vigorously for 30 seconds. Compare color of CCl. layer with 1-, 2-, 3-, and 4-microgram zinc standards similarly prepared.

\section{DIFFICULTIES AND PRECAUTIONS}

Some of the reagents, particularly carbon tetrachloride and potassium cyanide, are toxic and should be handled with care. No worker should attempt to use these reagents without becoming thoroughly familiar with the dangers involved and the precautions necessary in their use by reference to any competent work on laboratory toxicology, as for example Elkins (1950).

Dithizone in carbon tetrachloride solution is easily oxidized and rendered useless by light, heat, and excesses of ferric iron in the aqueous phase. The oxidation product is yellow, and its presence when mixed with unaltered-green dithizone can be determined by observing the yellow-green or dirty-green hue of the resulting solution. The effects of light and heat can be minimized by the use of the thermos dispenser described above. The effect of oxidation by ferric iron can under favorable conditions be offset by adding hydroxylamine hydrochloride, which acts as a reducing agent.

The most serious analytical difficulty encountered in the course of the field program in Nigeria was with the lead test, where reproducible results could not be obtained with either standard or sample solutions. At the beginning of the project reasonably good repeat analyses $293432-55-4$ 
could be obtained on samples previously run. The reproducibility became progressively worse until, in the latter part of the project, analysis for lead was abandoned because of inability to get consistent results. Later investigation showed that the difficulty apparently arose from cumulative impurities in the carbon tetrachloride after repeated redistillation. It was concluded that the impurity responsible for the difficulty was probably phosgene, which is known to be generated by distillation of impure carbon tetrachloride. Phosgene has the combined effect of acidifying the solution and destroying the lead-dithizone complex, and its presence could adequately account for all the difficulties encountered. Carbon tetrachloride contaminated with phosgene may be made suitable for use by a preliminary shaking with a strong aqueous solution of ammonia; or by distillation in the presence of $\mathrm{CaO}$.

\section{CHARACTERISTICS OF TESTS}

During the progress of the field work, 735 determinations for zinc and 698 determinations for lead were made in the field laboratory on 685 samples. Subequently, 533 of these samples and 485 additional samples were analyzed for lead and zinc in the laboratory in Denver, by the same procedure as was used in the field. Also 150 replicate determinations by the rapid procedures and 15 analyses by quantitative colorimetric methods were run in Denver. These data are the basis for the following appraisal of the characteristics of the rapid tests as used in Nigeria.

\section{PRODUCTIVITY}

Two African laboratory assistants were trained to do the analytical procedure through the digestion of samples. This work included measuring the sample into the test tube with a scoop, labeling the test tube, pipetting nitric acid into the tube, and boiling over the petrol burner for half an hour. The African help required some supervision for this, as they had difficulty in manipulating some of the equipment, particularly the petrol stove. Under ordinary operating conditions, these two men could process one hundred samples in a sixhour working day.

In 18 days spent on laboratory work at the field headquarters, a total of 1,433 determinations were made on 685 samples. This is equivalent to an over-all productivity of about 80 determinations per day, and about 35 samples per day, for the crew of one European with two African assitants.

\section{REPRODUCIBILITY}

The data from the replicate determinations of zinc on 504 samples, first in the field laboratory in Nigeria, and then in the Denver laboratory, are summarized in table 2. Bulk comparison of the two sets of data showed an unexplained systematic error equivalent to about a 
20-ppm deficiency in the field determinations. To make the data more nearly comparable, therefore, $20 \mathrm{ppm}$ has been added to the field data before tabulation in column 2 of table 2. Furthermore, the figures obtained in the field have been grouped for the sake of simplifying the computations. By way of explanation, the fourth horizontal line of table 2 is computed on the basis of 32 samples (column 1), all of which gave 100 or $110 \mathrm{ppm} \mathrm{Zn}$ according to the original determination in the field laboratory; to this is added $20 \mathrm{ppm}$ to compensate for systematic error, giving values that may be grouped as $125 \mathrm{ppm}$ (column 2) ; repeat determinations on each of these 32 samples in the Denver laboratory averaged $123 \mathrm{ppm} \mathrm{Zn}$ (column 3);9 of these replicates, or 36 percent (column 4) were reported $125 \mathrm{ppm} \mathrm{Zn} ; 27$, or 84 percent (column 5) were reported between $83 \mathrm{ppm}$ and $187 \mathrm{ppm}$; and 31 , or 97 percent (column 6) were reported between $62 \mathrm{ppm}$ and $250 \mathrm{ppm}$. In summary, the data of table 2 show that, with allowance for systematic error, 4 out of 5 of the pairs of replicate determinations differ by a factor of 1.5 or less, and that better than 9 out of 10 differ by a factor of 2.0 or less. Because of the difficulties encountered in the field with the lead procedure, and the resulting lack of reliability of the data, a similar study of lead determinations made in the field would be of no significance.

TABLE 2.-Comparison of replicate rapid determination of zino in Denver Laboratory with original determinations in field laboratory

\begin{tabular}{|c|c|c|c|c|c|}
\hline \multirow[b]{2}{*}{ Number of samples } & \multirow[b]{2}{*}{$\begin{array}{c}\text { Original } \\
\text { determi- } \\
\text { nation } \\
\text { in field } 1 \\
\text { (ppm) }\end{array}$} & \multirow[b]{2}{*}{$\begin{array}{c}\text { Mean of } \\
\text { repeat } \\
\text { determi- } \\
\text { nations } \\
\text { in labora- } \\
\text { tory (ppm) }\end{array}$} & \multicolumn{3}{|c|}{ Percent of repeat determinations- } \\
\hline & & & $\begin{array}{c}\text { Identical } \\
\text { to original } \\
\text { determi- } \\
\text { nation }\end{array}$ & $\begin{array}{c}\text { Within } \\
\text { +50 pct } \\
\text { and - }-33 \\
\text { pct of } \\
\text { original } \\
\text { determi- } \\
\text { nation }\end{array}$ & $\begin{array}{l}\text { Within } \\
+100 \text { pet } \\
\text { and -50 } \\
\text { pct of } \\
\text { original } \\
\text { determ!- } \\
\text { nation }\end{array}$ \\
\hline 1 & 2 & 3 & 4 & 5 & 6 \\
\hline $\begin{array}{l}44 \\
16\end{array}$ & $\begin{array}{r}\geq 250 \\
200 \\
150 \\
125 \\
100 \\
75 \\
50 \\
25\end{array}$ & $\begin{array}{r}187 \\
103 \\
123 \\
93 \\
72 \\
56 \\
41\end{array}$ & $\begin{array}{l}55 \\
25 \\
28 \\
36 \\
40 \\
31 \\
55 \\
61\end{array}$ & $\begin{array}{r}75 \\
100 \\
71 \\
84 \\
81 \\
92 \\
74 \\
61\end{array}$ & $\begin{array}{r}100 \\
100 \\
71 \\
97 \\
99 \\
92 \\
99 \\
82\end{array}$ \\
\hline
\end{tabular}

1 Figures in this column include $20 \mathrm{ppm}$ added to original determinations to compensate for an apparent systematic error. For simplicity, the values have been grouped; thus $50 \mathrm{ppm}$ includes original determinations of 40,50 , and $60 \mathrm{ppm}$.

Sets each consisting of ten samples for which the original determinations were the same were selected from the total of 1018 samples analyzed for lead and zinc in the Denver laboratory. Table 3, column 2 , gives the original determinations for lead and zinc. Each one of these samples was re-analyzed by the same procedure. Columns 3 to 6 
of table 3 are similar to the same columns in table 2. The conclusions to be drawn from these data are essentially the same as those enumerated for table 2 .

\section{ACCURACY}

Column 7 of table 3 gives the results of quantitative colorimetric determinations on composite samples representing each set. These values are probably accurate to within \pm 10 percent, and constitute a standard reference with which to compare the rapid determinations. It may be observed that the correspondence between rapid and quantitative determinations of lead is fairly good. The rapid determinations of zinc are substantially lower than the quantitative values, possibly as the result of incomplete extraction of zinc by the relatively weak half-hour digestion in nitric acid called for by the rapid procedure. It is difficult to explain the discrepancies in quantitative values between the sets containing high lead and low lead where the rapid zinc determinations were the same; it is likely that some lead is being reported as zinc in these samples.

TABLE 3.-Comparison of replicate rapid determination of lead and zinc in Denver laboratory

\begin{tabular}{|c|c|c|c|c|c|c|}
\hline \multirow[b]{2}{*}{ Number of samples } & \multirow[b]{2}{*}{$\begin{array}{l}\text { Original } \\
\text { rapid } \\
\text { determi- } \\
\text { nations } \\
(\mathrm{ppm})\end{array}$} & \multirow[b]{2}{*}{$\begin{array}{l}\text { Mean of } \\
\text { repeat } \\
\text { determi- } \\
\text { nations } \\
(\mathrm{ppm})\end{array}$} & \multicolumn{3}{|c|}{ Number of repeat determinations- } & \multirow[b]{2}{*}{$\begin{array}{l}\text { Quanti- } \\
\text { tative } \\
\text { determi- } \\
\text { nations of } \\
\text { composite } \\
\text { (ppm) }\end{array}$} \\
\hline & & & $\begin{array}{l}\text { Identical } \\
\text { with origi- } \\
\text { nal deter- } \\
\text { mination }\end{array}$ & $\begin{array}{l}\text { Within } \\
+50 \text { pct } \\
\text { and }-33 \\
\text { pct of } \\
\text { original } \\
\text { determi- } \\
\text { nation }\end{array}$ & $\begin{array}{l}\text { Within } \\
\text { +100 pct } \\
\text { and -50 } \\
\text { pct of } \\
\text { original } \\
\text { determi- } \\
\text { nation }\end{array}$ & \\
\hline 1 & 2 & 3 & 4 & 5 & 6 & 7 \\
\hline \multicolumn{7}{|c|}{ Lead } \\
\hline $\begin{array}{l}10 \\
10 \\
10 \\
10 \\
10 \\
10\end{array}$ & $\begin{array}{r}10,000 \\
5,000 \\
2,000 \\
1,000 \\
500 \\
200 \\
100 \\
50\end{array}$ & $\begin{array}{r}9,800 \\
3,600 \\
1,950 \\
715 \\
370 \\
190 \\
109 \\
52\end{array}$ & $\begin{array}{l}4 \\
1 \\
5 \\
3 \\
1 \\
6 \\
4 \\
5\end{array}$ & $\begin{array}{l}9 \\
5 \\
9 \\
5 \\
4 \\
8 \\
6 \\
5\end{array}$ & $\begin{array}{r}10 \\
9 \\
10 \\
9 \\
10 \\
10 \\
10 \\
10\end{array}$ & $\begin{array}{r}8,000 \\
4,700 \\
2,125 \\
900 \\
430 \\
220 \\
98 \\
45\end{array}$ \\
\hline \multicolumn{7}{|c|}{ Zine } \\
\hline $\begin{array}{l}10 \\
10 \\
10 \\
10 \\
10\end{array}$ & $\begin{array}{r}1,000 \\
500 \\
200 \\
1100 \\
2100 \\
150 \\
250\end{array}$ & $\begin{array}{r}1,170 \\
513 \\
149 \\
91 \\
101 \\
61 \\
54\end{array}$ & $\begin{array}{l}2 \\
1 \\
1 \\
2 \\
4 \\
3 \\
5\end{array}$ & $\begin{array}{l}4 \\
8 \\
8 \\
4 \\
6 \\
6 \\
7\end{array}$ & $\begin{array}{r}9 \\
9 \\
8 \\
9 \\
10 \\
10 \\
10\end{array}$ & $\begin{array}{r}1,800 \\
660 \\
300 \\
200 \\
125 \\
160 \\
70\end{array}$ \\
\hline
\end{tabular}

1 Lead by original rapid determination $\overline{500} \mathrm{ppm}$.

${ }^{2}$ Lead by original rapid determination $₹ 100 \mathrm{ppm}$.

\section{SHIPMENT OF SAMLPES}

At the end of the field project, all the soil and rock samples were shipped to the Geological Survey laboratory in Denver, Colo. All 
the data used in this report are from the subsequent analytical work by this laboratory.

Restrictions on international shipments of materials from tropical countries posed serious problems at the start of the investigations in Nigeria and should be studied carefully whenever geochemical work is contemplated in the tropics. Where soil or plant samples are imported from tropical countries into the United States, special prior arrangements must be made with the Bureau of Entomology and Plant Quarantine of the U. S. Department of Agriculture in Washington, D. C., or the shipment is liable for confiscation and destruction. For example, when the soils were imported from Nigeria, an arrangement was made whereby the shipment was entered without inspection on the condition that all the samples would be sterilized at $105^{\circ} \mathrm{C}$ for one hour before they were discarded. No similar regulations apply to imports into the United Kingdom.

\section{DISTRIBUTION OF LEAD AND ZINC}

A large part of the geochemical prospecting work in the Nyeba district was devoted to fairly detailed studies of the distribution of lead and zinc in surficial materials, both in mineralized and in unmineralized localities. Most of this experimental work was in the vicinity of the Palm Wine, Ameri and Ameka lodes, and the Crocodile prospect (fig. 2).

The data from each of these localities has contributed to the solution of several problems in the distribution of lead and zinc. Therefore, in the following discussion, the results of the experiments will be arranged according to the various topics under consideration rather than according to the localities where the work was conducted.

\section{GOSSAN}

The Ameka and Nyeba lodes are characterized by strongly silicified wall rocks that are relatively resistant to erosion. As a result, these lodes crop out along low ridge tops, where the limonitic oxidation products of the sulfide minerals have been preserved by the protecting sheath of silicified shale. Work by J. H. Courtright, resident geologist at the mines, showed that it was possible to identify the primary minerals of these lodes, particularly marcasite, siderite, and sphalerite, by the texture of the secondary limonitic pseudomorphs in the gossan. With much of the limonitic material, even from these lodes, however, identification of the parent minerals was uncertain or impossible.

None of the other lodes of the Nyeba district showed the same degree of wall-rock silicification or topographic relief. Where the oxidized outcrops of the lodes are not protected from erosion, gossan material is seen on the surface only as small fragments of limonite scattered through the surface rubble, and shows no diagnostic relict textures. 
In an attempt to find a more generally useful method of appraising the base-metal content of the parent lode, a collection of gossan samples was analyzed for lead and zinc (table 4). One group of samples was collected from the outcrop of the Ameka lode, which is known to be fairly rich in both lead and zinc; another group was taken from the Igbaja prospect, where the geochemical soil traverse directly over the ancient pit showed a well-developed zinc anomaly, but little or no pattern in lead. Characteristic pseudomorphic textures in the limonite could not be identified in any of these samples.

The results clearly show a high lead content of the Ameka samples, and a high zinc content of the Igbaja samples. Considerably more work of a similar nature over other lodes of known tenor will be necessary, however, before the metal content of limonite can be considered a reliable guide to the mineralogy of the parent lode. Nevertheless, the presence of relatively high concentrations of lead and zinc in. limonite may provide some evidence for the presence of base metals in a deposit where no primary sulfides can be observed.

TABLE 4.-Lead, zinc, and iron content of gossan samples

\begin{tabular}{|c|c|c|c|c|c|}
\hline \multirow{2}{*}{ Locallty } & \multirow{2}{*}{$\begin{array}{c}\text { Sam- } \\
\text { ple } \\
\text { no. }\end{array}$} & \multirow{2}{*}{$\begin{array}{l}\text { Per- } \\
\text { cent } \\
\text { Fe }\end{array}$} & \multicolumn{2}{|c|}{ ppm } & \multirow{2}{*}{ Remarks } \\
\hline & & & $\mathrm{Pb}$ & $\mathrm{Zn}$ & \\
\hline Ameka lode.......... & $\begin{array}{l}1627 \\
1628 \\
1629 \\
1630 \\
1631\end{array}$ & $\begin{array}{r}45.0 \\
5.6 \\
46.0 \\
4.9 \\
37.0\end{array}$ & $\begin{array}{l}5,000 \\
3,000 \\
3,000 \\
4,000 \\
3,000\end{array}$ & $\begin{array}{r}1,500 \\
500 \\
300 \\
900 \\
300\end{array}$ & $\begin{array}{l}\text { Limonitic boxwork; yellow-brown, siliceous. } \\
\text { Siliceous core; spongy, red limonitic coating. } \\
\text { Limonitic boxwork; yellow-brown, siliceous. } \\
\text { Siliceous skeleton filled with spongy red limonite. } \\
\text { Limonite, hard, banded, reddish-black with } \\
\text { slliceous stringers. }\end{array}$ \\
\hline Igbaja prospect....... & $\begin{array}{r}1632 \\
579 \\
580 \\
581 \\
582 \\
583 \\
584 \\
585\end{array}$ & $\begin{array}{l}50.0 \\
22.5 \\
22.0 \\
24.0 \\
48.0 \\
22.0 \\
28.0 \\
51.0\end{array}$ & $\begin{array}{r}150 \\
100 \\
700 \\
50 \\
50 \\
70 \\
50 \\
50\end{array}$ & $\begin{array}{r}80 \\
80,000 \\
10,000 \\
6,000 \\
180 \\
8,000 \\
200 \\
10,000\end{array}$ & $\begin{array}{l}\text { Limonite; hard, massive, reddish-black. } \\
\text { Limonite, amorphous, red. } \\
\text { Limonite, amorphous, yellow; with quartz. } \\
\text { Limonite, yellow. } \\
\text { Limonite, hard, black and brown. } \\
\text { Siderite with limonitic coating. } \\
\text { Limonitic boxwork, siliceous. } \\
\text { Do. }\end{array}$ \\
\hline
\end{tabular}

Relict galena crystals encased in a shell of white lead sulfate occur commonly in surficial materials near sulfide veins. Sulfate-coated galena fragments, rather than limonitic gossan, appear to be the normal product of the weathering of primary galena in the Nyeba district. Apparently galena is much more resistant to oxidation than the other ore-forming sulfides, as similar relict crystals of sphalerite or marcasite are never encountered in undisturbed surface soils.

\section{VERTICAL DISTRIBUTION IN RESIDUUM}

\section{WEATHERING PROFILE OVER UNMINERALIZED ROCKS}

Six suites of samples representing weathering profiles over five types of normal, unmineralized rocks, were collected to determine the behavior of lead, zinc, silica, iron, and alumina in the weathering cycle. The results are given in table 5. Shale, diorite, and biotite gneiss pro- 
files were sampled in well-drained areas of relatively low relief that are characterized by lateritic weathering. The micaceous and siliceous schist profiles were sampled in an area of fairly rugged topography where no signs of lateritic-type weathering were seen.

TABLE 5.-Distribution of certain elements in weathering profiles over unmineralized rocks

\begin{tabular}{|c|c|c|c|c|c|c|c|c|}
\hline \multirow{2}{*}{ Parent rock } & \multirow{2}{*}{ Type of weathering } & \multirow{2}{*}{ Zone } & \multicolumn{3}{|c|}{ Percent } & \multicolumn{3}{|c|}{ Parts per million } \\
\hline & & & $\mathrm{SiO}_{2} 1$ & $\mathrm{Fe}_{3} \mathrm{O}_{3} \mathrm{I}$ & $\mathrm{Al}_{2} \mathrm{O}_{8}{ }_{2}$ & $\mathrm{~Pb}$ & $\mathrm{Zn}$ & $\mathrm{Sb}$ \\
\hline $\begin{array}{l}\text { Shale (Nyeba dis- } \\
\text { trict). }\end{array}$ & $\begin{array}{l}\text { Lateritic, well- } \\
\text { drained. }\end{array}$ & $\begin{array}{l}\text { Laterite } \\
\text { Lateritic soil } \\
\text { Partly weathered } \\
\text { rock. }\end{array}$ & $\begin{array}{l}36.4 \\
55.2 \\
51.6\end{array}$ & $\begin{array}{l}41.1 \\
12.1 \\
11.2\end{array}$ & $\begin{array}{l}14.6 \\
17.4 \\
22.2\end{array}$ & $\begin{array}{r}114 \\
75 \\
67\end{array}$ & $\begin{array}{r}81 \\
155 \\
160\end{array}$ & \\
\hline $\begin{array}{l}\text { Diorite (Abaka- } \\
\text { liki). }\end{array}$ & -...do do & $\begin{array}{l}\text { Fresh rock } \\
\text { Laterite } \\
\text { Lateritic soil } \\
\text { Partly weathered } \\
\text { rock. }\end{array}$ & $\begin{array}{l}57.2 \\
17.0 \\
51.4 \\
45.9\end{array}$ & $\begin{array}{r}7.2 \\
53.5 \\
12.4 \\
9.9\end{array}$ & $\begin{array}{l}20.2 \\
14.2 \\
14.0 \\
13.8\end{array}$ & $\begin{array}{r}280 \\
210 \\
35\end{array}$ & $\begin{array}{r}226 \\
176 \\
40\end{array}$ & \\
\hline $\begin{array}{c}\text { Biotite gneiss (4 } \\
\text { miles } \mathrm{N} \text { of } \\
\left.\text { Obudu }{ }^{2}\right) .\end{array}$ & .... do do . . & $\begin{array}{l}\text { Laterite } \\
\text { Fresh rock }\end{array}$ & $\begin{array}{l}44.4 \\
66.8\end{array}$ & $\begin{array}{r}33.2 \\
6.8\end{array}$ & $\begin{array}{l}14.6 \\
15.3\end{array}$ & $\begin{array}{l}64 \\
19\end{array}$ & $\begin{array}{l}48 \\
85\end{array}$ & \\
\hline $\begin{array}{l}\text { Micaceous schist } \\
\text { (20 miles } \mathbf{E} \text { of } \\
\text { Obudu). }\end{array}$ & $\begin{array}{l}\text { Nonlateritic, well- } \\
\text { drained. }\end{array}$ & $\begin{array}{l}\text { Soil } \\
\text { Partly weathered }\end{array}$ & $\begin{array}{l}64.6 \\
66.5 \\
\end{array}$ & $\begin{array}{l}8.2 \\
8.1\end{array}$ & $\begin{array}{l}15.8 \\
15.0\end{array}$ & 64 & $\begin{array}{l}110 \\
130\end{array}$ & \\
\hline $\begin{array}{l}\text { Siliceous schist (20 } \\
\text { miles E of } \\
\text { Obudu). }\end{array}$ & .....do.. & $\begin{array}{l}\text { Fresh rock } \\
\text { Soil } \\
\text { Partly weathered } \\
\text { rock. }\end{array}$ & $\begin{array}{l}64.6 \\
73.6 \\
74.1\end{array}$ & $\begin{array}{l}8.6 \\
1.3 \\
2.4\end{array}$ & $\begin{array}{l}15.4 \\
15.6 \\
14.8\end{array}$ & $\begin{array}{l}23 \\
50 \\
65\end{array}$ & $\begin{array}{r}130 \\
32 \\
41\end{array}$ & $\mid-\ldots$ \\
\hline $\begin{array}{l}\text { Shale (Crocodile } \\
\text { prospect). }\end{array}$ & $\begin{array}{l}\text { Clay-type, poorly } \\
\text { drained. }\end{array}$ & $\begin{array}{l}\text { Organic clay, 3- } \\
\text { inch depth. } \\
\text { Gray clay, 24-inch } \\
\text { depth. } \\
\text { Mot t le d cla y, } \\
\text { 120-inch depth. } \\
\text { Fresh rock......... }\end{array}$ & $\begin{array}{l}61.8 \\
71.5 \\
57.2\end{array}$ & $\begin{array}{l}3.6 \\
6.0 \\
7.3 \\
7.2\end{array}$ & $\begin{array}{l}19.1 \\
12.9 \\
20.2\end{array}$ & $\begin{array}{l}55 \\
23 \\
20\end{array}$ & $\begin{array}{r}84 \\
161 \\
93\end{array}$ & - \\
\hline
\end{tabular}

1 Analyses by K. E. White, J. M. Dowd, and H. F. Phillips, U. S. Geological Survey, Beltsville, Md. $2 \bar{O} ' b \overline{00} \cdot d \overline{00} ')$.

The samples representing the lateritic profile over shale were taken from different parts of the Nyeba district, as the entire profile was not exposed at any one locality. Therefore, much of the chemical variation in the weathering products may be a reflection only of the variations in the composition of the parent rock. The diorite and biotite gneiss suites were collected from single localities, although, here again, local, undetermined variations in the composition of the parent rocks will be responsible for corresponding variations in the weathering products. Each of the schist suites came from the walls of an excavation where samples could be collected from a single layer extending from the surface down into relatively unweathered rock.

The samples from the lateritic profiles all show an enrichment of iron and lead and an impoverishment of silica in the course of weathering and laterite formation. Zinc is impoverished in the samples of laterite derived from shale and gneiss and is enriched in the laterite over the diorite. The alumina content shows no significant trend.

In the nonlateritic profiles over schists, the data show no systematic variation in any of the elements reported. 
The clay-type weathering profile was sampled in the trench in the swamp near the Crocodile prospect (fig. 2). The figures in table 5 for the clay-type profile over shale represent analyses of composite samples of each zone collected along the 100-foot length of the trench. This profile is described in the discussion on Weathering in poorly drained areas. The sample of "fresh rock" used in both shale profiles was taken from Palm Wine bore hole 1. These data indicate that, at least in the trench near the Crocodile prospect, lead is enriched and iron impoverished in the organic surface horizon, whereas zinc is highest at a two-foot depth.

\section{WEATHERING PROFILE OVER KNOWN LODES}

To determine the distribution of lead and zinc with depth in the vicinity of a known sulfide vein, the sides of a small trench at the south end of the Ameri lode were sampled (figs. 3 and 4). In this area, the original, natural surface had apparently not been disturbed by prehistoric mining activity, so that the soil was probably relatively uncontaminated. Sets of two samples, one of fragmental material at a depth of 6 inches and the other of weathered shale at a depth of 2 feet, were collected at horizontal intervals of five feet along the length of the trench. No laterite zone was present. Table 6 shows the average lead and zinc content of soil and weathered shale from this trench.

TABLE 6.-Distribution of lead and zino in weathering profiles over known lodes

\begin{tabular}{|c|c|c|c|c|c|}
\hline \multirow{2}{*}{ Lode } & \multirow{2}{*}{ Zone } & \multirow{2}{*}{$\begin{array}{l}\text { Number } \\
\text { of samples } \\
\text { analyzed }\end{array}$} & \multirow{2}{*}{$\begin{array}{c}\text { Depth } \\
\text { (inches) }\end{array}$} & \multicolumn{2}{|c|}{ Parts per million } \\
\hline & & & & $\mathrm{Pb}$ & Zn \\
\hline Ameri & Soil _... & 10 & 6 & 7,500 & 1,090 \\
\hline Palm Wine.. & $\begin{array}{l}\text { Weathered shale. } \\
\text { Soil } \\
\text { Laterite } \\
\text { Weathered shale. }\end{array}$ & $\begin{array}{r}10 \\
6 \\
6 \\
6\end{array}$ & $\begin{array}{r}24 \\
6 \\
24 \\
96\end{array}$ & $\begin{array}{l}5,300 \\
7,800 \\
1,140 \\
3,700\end{array}$ & $\begin{array}{r}1,460 \\
166 \\
91 \\
425\end{array}$ \\
\hline
\end{tabular}

A similar study was made at trench A (figs. 5 and 6 ) near the north end of the Palm Wine lode, where a narrow vein of galena was exposed. The principal feature displayed by this trench was the occurrence at a depth of 6 inches of a laterite zone about $31 / 2$ feet thick. Weathered shale lay immediately below the laterite. Sets of three samples, one of surface material, one of laterite, and one of the weathered shale at the bottom of the trench, were collected at horizontal intervals of 10 feet. The average lead and zinc content of the soil, laterite, and weathered shale in the six profiles east of the vein is given in table 6.

These data conform in general with the common observation that lead is enriched and zinc is impoverished in soils, as compared with the parent rock. At the Palm Wine locality, the content of both lead and 


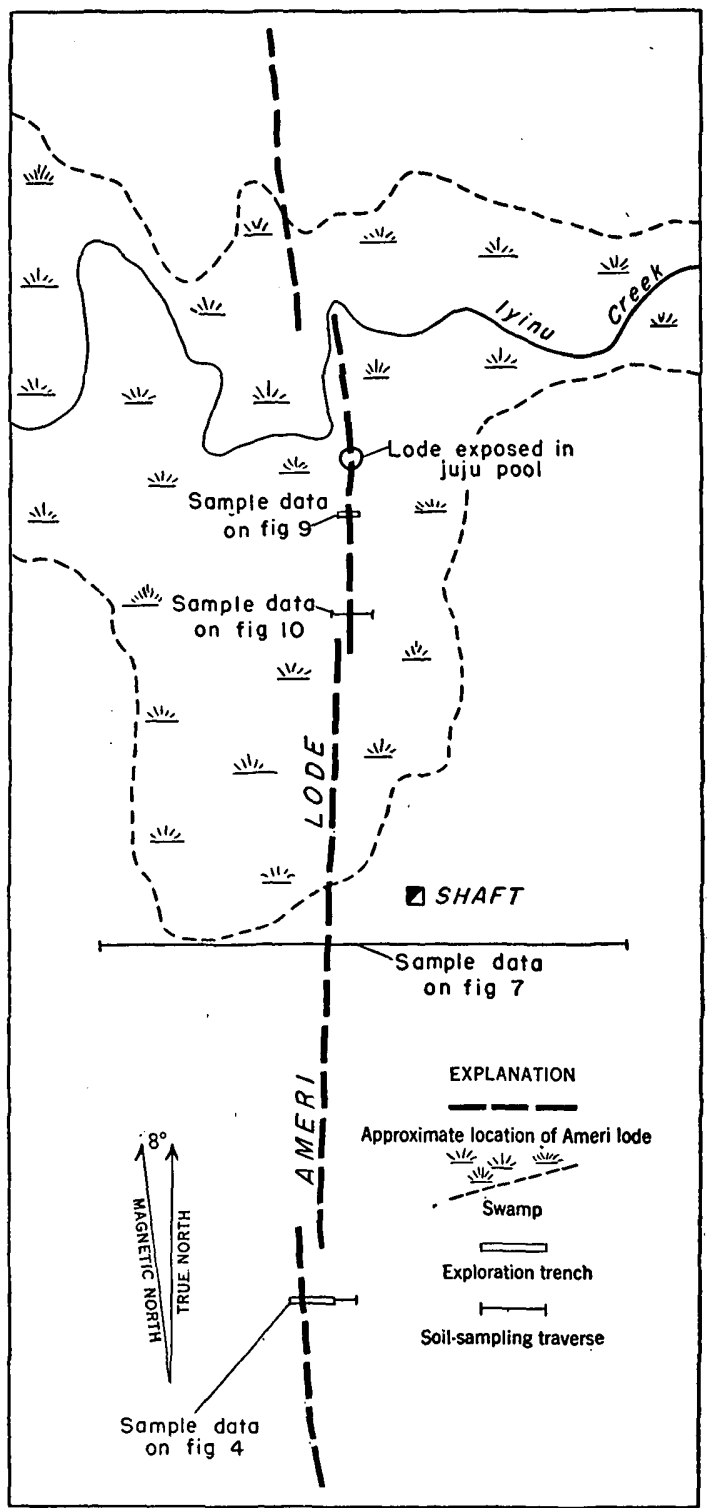

Bose map from survey by Nigerion

Lead-Zinc Mining Company

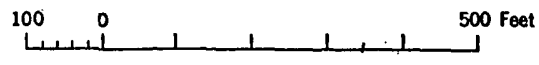

Fraure 3.-Map of Ameri lode. 

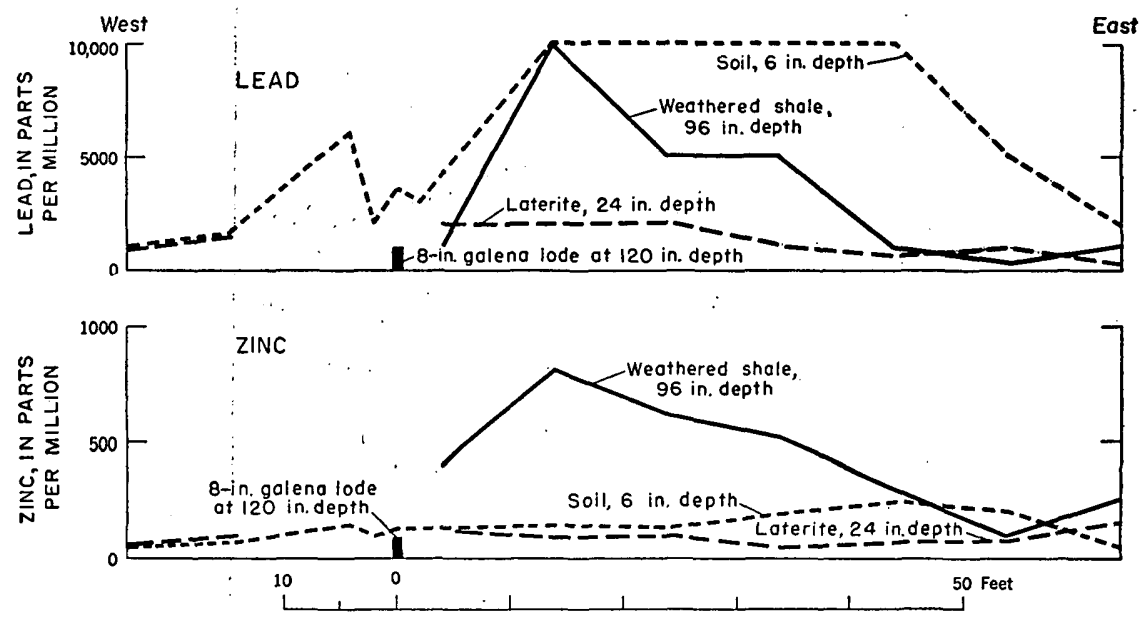

Frgore 4.-Vertical distribution of metal over Ameri lode.

zinc in the laterite is less than that in the associated soil and weathered rock, although at least the lead content is well above background for laterite over unmineralized rock. From this, it may be concluded that for reconnaissance geochemical exploration in well-drained areas samples of surface soil analyzed for either lead or zinc will be just about as effective in locating buried lead-zinc lodes as samples of material from greater depth, in spite of a certain amount of leaching or enrichment in the course of weathering.

A similar study was not made of the distribution of lead and zinc in a clay-type weathering profile over a known bedrock sulfide deposit. Such an experimental study would be well worth making, if a place could be found where clay soil of definitely residual origin overlies a known lode.

\section{LATERAI DISTRIBUTION IN RESIDUUM}

\section{TRENCHES OVER PALM WINE AND AMERI LODES}

The data presented in figures 4 and 6 also show a lateral dispersion of lead and zinc from a relatively narrow sulfide vein over a distance of several tens of feet and each side of the vein, both in the soil and in the underlying laterite and weathered rock. In the Ameri trench, a higher than normal metal content occurs in the soil across a width of at least 55 feet; at the Palm Wine trench, the minimum width is 90 feet, Within these limits the distribution pattern of metals in the soil, laterite or weathered shale does not appear to correspond in detail with the location of the veins where they are exposed in the trenches. From this, it may be concluded that samples of lateritic soil collected at intervals of fifty feet would have been adequate to show the existence of either of these veins; samples taken at closer spacing, however, 


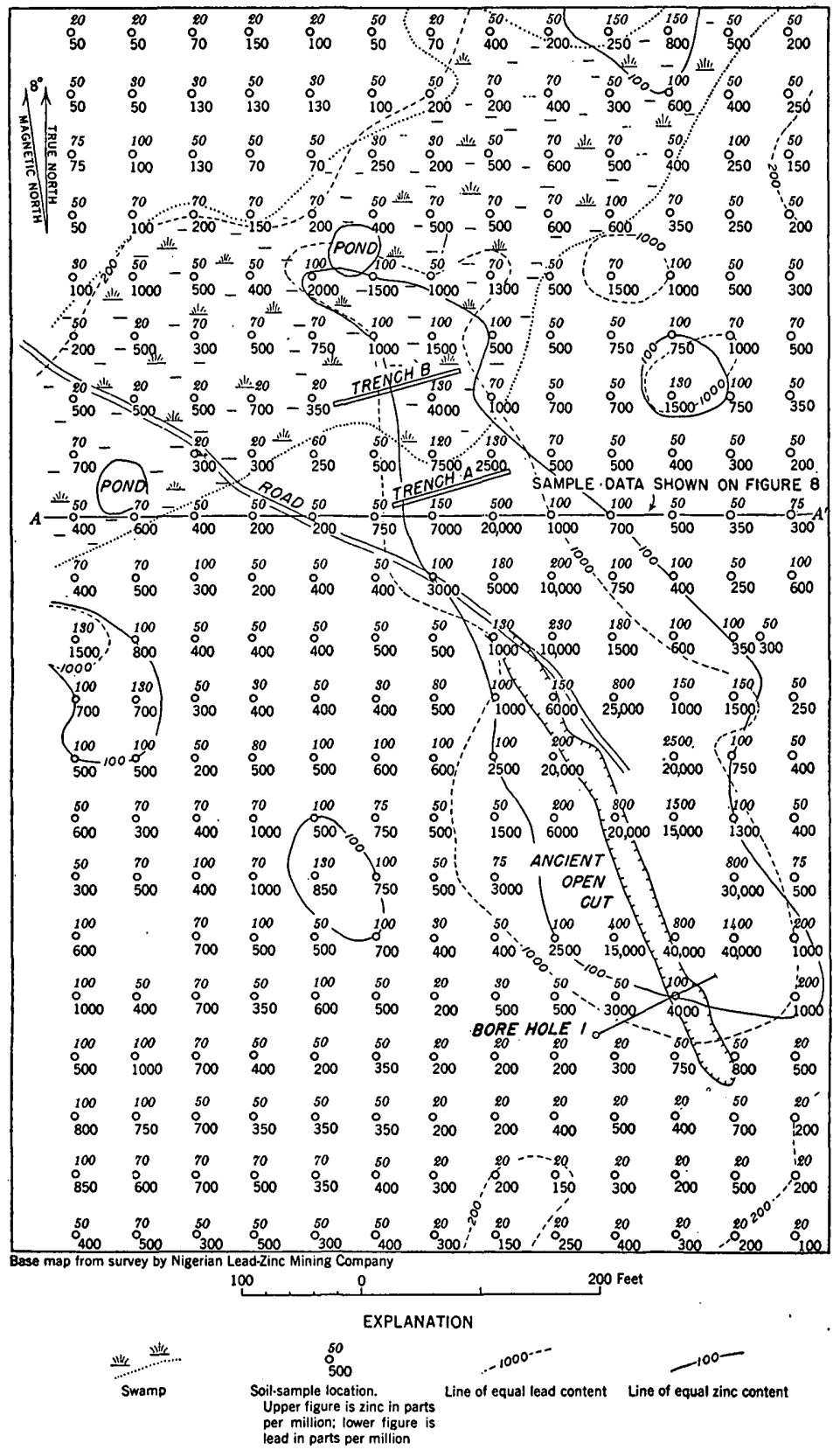

Fig URe 5.-Geochemical soil survey, Palm Wine lode. 

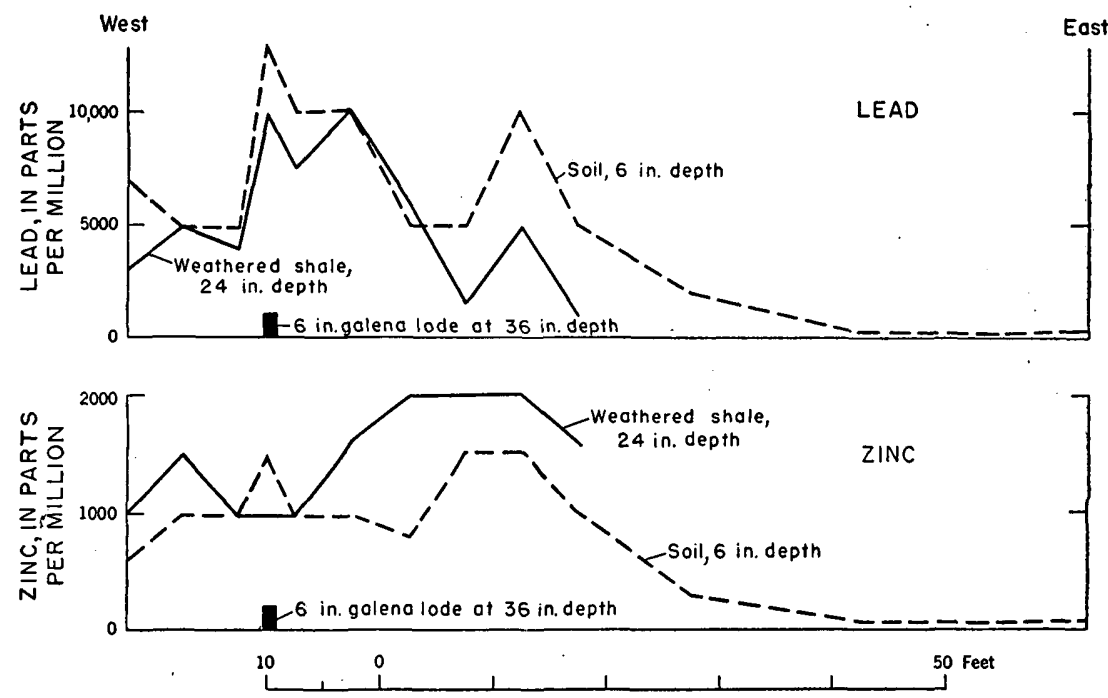

Fiourd 6.-Vertical distribution of metal over Palm Wine lode.

would not have provided very much additional information as to the exact location of the veins.

\section{TRAVERSE ACROSS AMERI LODE}

Figure 7 shows the distribution of lead, zinc, and antimony in lateritic soil samples collected at 50-foot intervals across the Ameri lode, at a point 300 feet north of the ternch discussed above (fig. 3 ). Because of contamination of the surficial material by nearby excavations, a significant sample could not be obtained directly over the vein. The metal content of soil samples on each side of the vein indicate that the lead and zinc anomalies here are in the order of 200 feet wide, as compared with a lode width at this point of less than 10 feet. The economic threshold of this anomaly is about $100 \mathrm{ppm}$ for both lead and zinc. The distribution of antimony in soils shows no apparent correlation with the location of the lode.

\section{TRAVERSE ACROSS PALM WINE LODE}

Samples from a traverse across the Palm Wine lode, the location of which is shown as Section $A-A^{\prime}$ on figure 5, were analyzed for lead, zinc, copper, cobalt, nickel, silver, arsenic, and antimony. As shown in figure 8, the lead and zinc anomalies here are more than 100 feet wide, on the assumption of economic thresholds of $1,000 \mathrm{ppm}$ for lead and $100 \mathrm{ppm}$ for zinc. Of the other metals, only silver and antimony formed significant distribution patterns. Silver content was $0.6 \mathrm{ppm}$ in the sample containing maximum lead and zinc, and less than $0.2 \mathrm{ppm}$ in all the other samples. The antimony pattern is very similar to the patterns of both lead and zinc. The copper content of these samples 


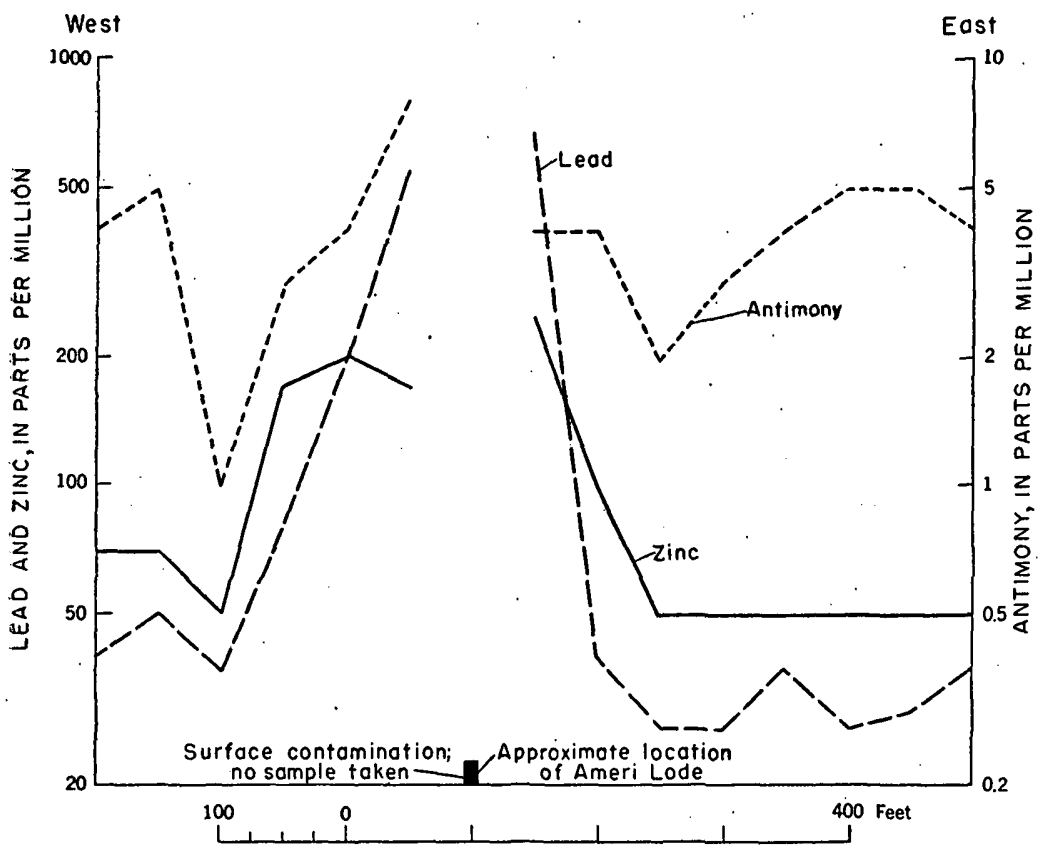

Figdre 7.-Metal content of soll over Ameri lode.

shows very weak correlation with the location of the lode. Cobalt content was $10 \mathrm{ppm}$ in the sample directly over the lode, and less than $10 \mathrm{ppm}$ in all others. Nickel content was less than $30 \mathrm{ppm}$ and arsenic less than $10 \mathrm{ppm}$ in all samples.

\section{GRID OVER PALM WINE LODE}

Near-surface soil was sampled on 50-foot centers in an area 600 by 1,000 feet adjoining the Palm Wine lode (fig. 5). Most of this area is well drained and mantled with lateritic soil, although a broad stream channel flanked by clay soil crosses the north part of the map area.

The southern part of the lode had at one time been mined by opencast methods, undoubtedly resulting in some scattering of metal-rich material and contamination of the soil in the immediate vicinity. Soil samples were not taken unless the ground appeared to be undisturbed, and thus less likely to be contaminated. In spite of the uncertainty regarding contamination, it is believed that the pattern appearing on the map is probably not very different from what would have been found if the lode had never been worked.

Inspection of the data presented in figure 5 shows that the $100 \mathrm{ppm}$ $\mathrm{Zn}$ contour and the $1,000 \mathrm{ppm} \mathrm{Pb}$ contour effectively outline the location of the known lode and its probable extensions. The width of the metal-rich zone thus defined ranges from 100 to 250 feet wide. Reconnaissance traverses sampled even at 100 -foot intervals therefore would not have failed to locate the Palm Wine lode. A unique feature of the 


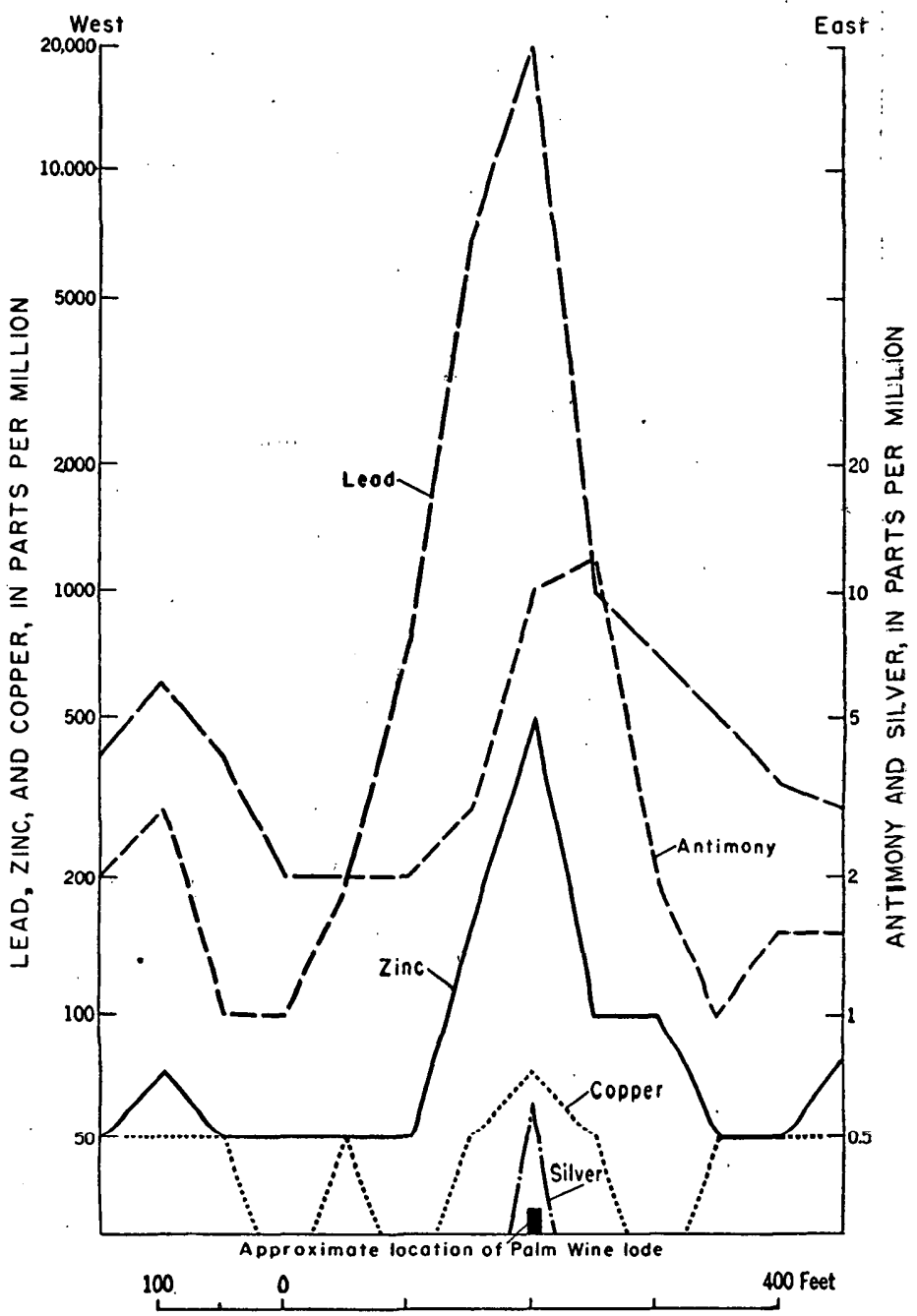

Fradri 8.- Metal content of goil over Palm wine lode along section $\Delta-\Delta$ : 
Palm Wine area is the high lead background in the soils, averaging almost $500 \mathrm{ppm}$, as contrasted with a normal background of 30 to $50 \mathrm{ppm} \mathrm{Pb}$. The significance of the local high background in lead will be discussed later in connection with the distribution of metals in rocks.

The belt of clay soil in the northern part of the Palm Wine area is interpreted as residual rather than alluvial. The anomaly in lead and zinc extends from the area of lateritic soil northward into the area of clay soil, with no discontinuity at the boundary except for a decrease in the maximum lead and zinc content. The gradational character of the bottom contact of the clay profile with underlying weathered shale where it was exposed in exploration trench B (fig. 5) also indicates a residual origin for the clay cover. Furthermore, if the clay were alluvial, one would expect that the anomalous pattern of metals in the clay would curve to the northeast following the direction of stream drainage.

The lead and zinc content of the soils north of the stream channel is markedly different from that to the south. Both the geochemical anomaly corresponding to the Palm Wine lode and the area of high lead background end at the stream channel. This abrupt change in the geochemical pattern suggests that the stream here may be coincident with an important fault, contact, or other bedrock structure.

\section{DISTRIBUTION IN ALLUVIAL COVER}

A trench across the suboutcrop of the Ameri lode in the poorly drained swampy area flanking Iyinu stream (fig. 3) exposed a 6- to 8foot section of clay cover believed to be of alluvial origin.

The lode where it is exposed in the trench is about 6 feet wide, and dips $70^{\circ}$ to the west (fig. 9). Both the lode minerals and the shale country rock appear to be relatively unweathered. On one side of the lode, the shale country rock is overlain by a wedge of conglomeratic material containing rounded fragments of sulfide minerals, gossan, and shale cemented with limonite. A knife-edge contact separates the clay cover from both the bedrock and the limonitic conglomerate. Except for the sharp basal contact of the clay, the profile is superficially indistinguishable from that observed in the residual clay exposed in the trench near the Crocodile prospect. The surficial foot or so is even-hued gray clay, overlying a mottled red and gray clay which extends to the surface of bedrock. Although the clay cover shows no immediately apparent sedimentary structure, careful probing with a blade indicated the presence of horizontal layers an inch or so thick containing relatively gritty material. Scattered, rounded fragments of weathered shale, gossan, galena, and charcoal up to an inch in diameter are distributed apparently at random throughout the clay. The fragments of charcoal show relict growth 


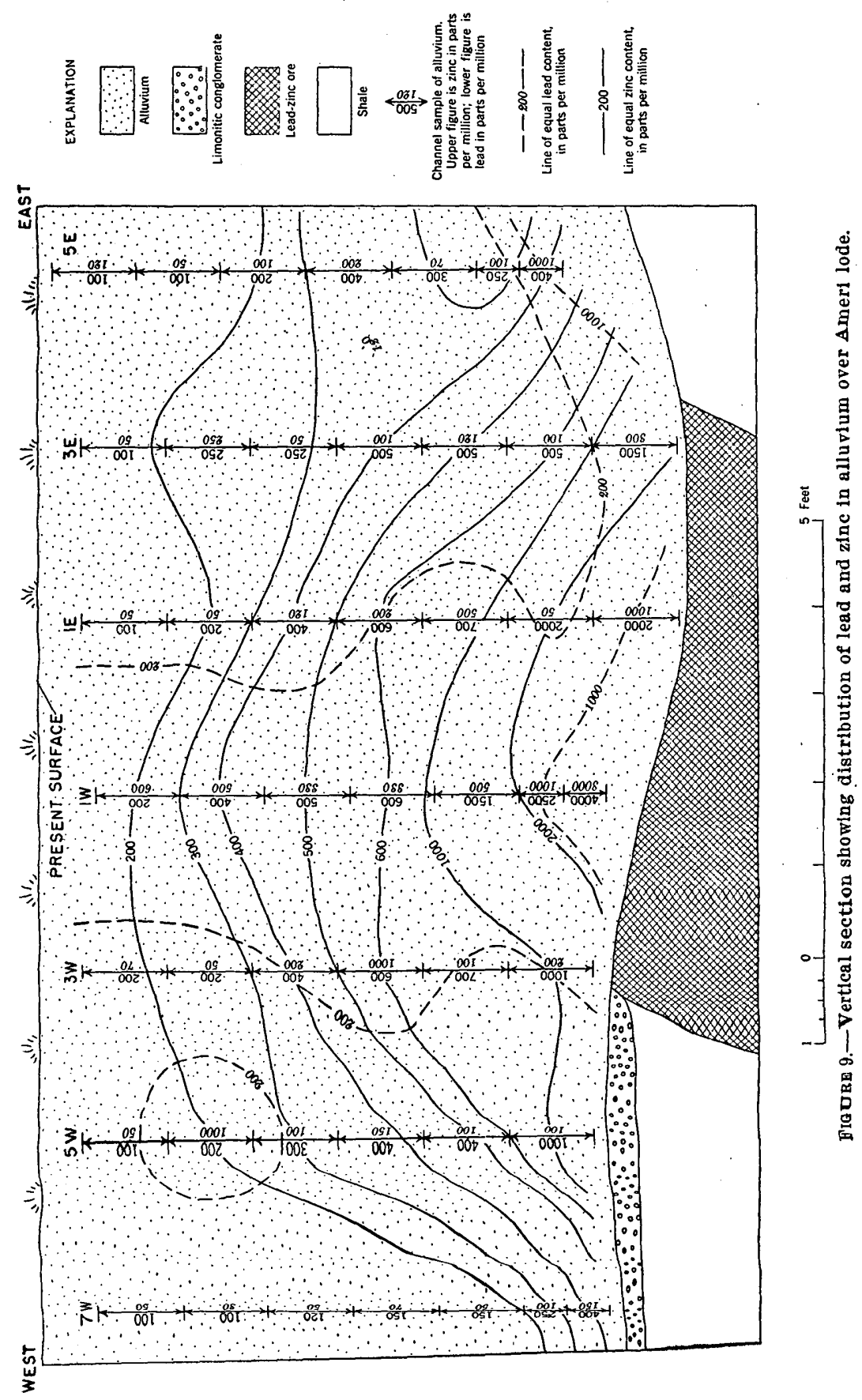

4 
rings indicating that they are the carbonization product of wood rather than of roots. The sharp basal contact of the clay and the presence of charcoal are interpreted as good evidence that the clay deposit is of sedimentary origin and is made up of alluvial material brought into the basin by sheet wash from the surrounding higher ground. It is probable that this deposit was laid down as part of the catastrophic cycle of soil erosion that followed the clearing of the forests several hundred years ago.

Vertical channel samples of the clay profile were collected by cutting out shallow grooves in the wall of the trench with a pocket knife, and placing all cuttings from the section sampled in a container. In this manner, 11 profiles were sampled in sections of one foot or less. Analytical results from these samples are shown in table 7 and figure 9 ; the profiles are numbered according to the distance in feet east or west of the center of the vein.

These data show a systematic distribution of both lead and zinc with respect to the suboutcrop of the lode. In sectional view, the lead as outlined by the 200-ppm contour is distributed both in a chimneylike pattern extending upward from the lode, and in a layer extending horizontally along the surface of bedrock for about 10 feet east of the east contact of the lode. The lines of equal zinc content form more of a domelike pattern over the suboutcrop of the ore. In addition to the dome pattern, a layer of clay containing more than 300 ppm zinc extends horizontally along the surface of bedrock east of the lode for at least 20 feet.

TABLE 7.-Lead and zinc content of alluvial cover over Ameri lode

\begin{tabular}{|c|c|c|c|c|c|c|c|}
\hline \multirow{2}{*}{ Feet above bedrock } & \multicolumn{7}{|c|}{$\begin{array}{c}\text { Lead and zinc content, parts per million for indicated distance from } \\
\text { lode, in feet }\end{array}$} \\
\hline & $24 \mathrm{~W}$ & $14 \mathrm{~W}$ & $6 \mathrm{~W}$ & 0 & $6 \mathrm{E}$ & $16 \mathrm{E}$ & $26 \mathrm{E}$ \\
\hline \multicolumn{8}{|c|}{ Lead. } \\
\hline $\begin{array}{l}7-8 \\
6-7 \\
6-6 \\
4-5 \\
3-4 \\
2-3 \\
1-2\end{array}$ & \begin{tabular}{l|} 
\\
50 \\
50 \\
50 \\
50 \\
50 \\
50
\end{tabular} & $\begin{array}{l} \\
70 \\
50 \\
50 \\
90 \\
50 \\
50\end{array}$ & $\begin{array}{r}50 \\
30 \\
50 \\
70 \\
50 \\
125\end{array}$ & $\begin{array}{r}600 \\
500 \\
330 \\
330 \\
500 \\
2,000\end{array}$ & $\begin{array}{r}120 \\
50 \\
100 \\
200 \\
70 \\
550 \\
-\end{array}$ & $\begin{array}{r}50 \\
50 \\
70 \\
100 \\
100 \\
200 \\
1,500\end{array}$ & $\begin{array}{l}40 \\
50 \\
50 \\
50 \\
50 \\
50 \\
70 \\
60\end{array}$ \\
\hline \multicolumn{8}{|c|}{ Zinc } \\
\hline $\begin{array}{l}7-8 \\
6-7 \\
5-6 \\
4-5 \\
3-4 \\
2-3 \\
1-2 \\
0-1\end{array}$ & $\begin{array}{l}100 \\
100 \\
100 \\
100 \\
100 \\
100\end{array}$ & $\begin{array}{l}100 \\
100 \\
100 \\
125 \\
150 \\
200\end{array}$ & $\begin{array}{l}100 \\
100 \\
120 \\
150 \\
150 \\
325\end{array}$ & $\begin{array}{r}200 \\
400 \\
500 \\
600 \\
1,500 \\
3,250\end{array}$ & $\begin{array}{l}100 \\
100 \\
200 \\
400 \\
300 \\
325\end{array}$ & $\begin{array}{l}100 \\
100 \\
150 \\
200 \\
250 \\
300 \\
400\end{array}$ & $\begin{array}{r}75 \\
50 \\
75 \\
50 \\
200 \\
250 \\
350 \\
750\end{array}$ \\
\hline
\end{tabular}


The systematic relationship of the distribution of lead and zinc to the position of the suboutcrop of the sulfide lode strongly suggests that these anomalies have been developed by movement of metal from a source in the lode up into the overlying clay, where it has been fixed: If the age of the alluvial deposit, as inferred, is about 400 years, the rate of dispersion of lead and zinc in the formation of superimposed halos of this kind would be fairly well established.

The width of the halo studied in the Ameri trench is hardly more than the width of the vein itself. If $300 \mathrm{ppm}$ zinc is taken as the threshold, the zinc anomaly 2 feet above the surface of bedrock has a width of about 10 feet. Thus in exploration, the location of a geochemical indication of a vein 6 feet wide covered by recent alluvium would require a maximum spacing of samples of not much more than 5 feet.

To test this conclusion, a series of samples were collected across the lode 100 feet south of the trench (fig. 3). Samples were taken at 5 -foot intervals and from a depth of 4 feet below the surface. The total depth to bedrock was not known. Figure 10 shows the distri-

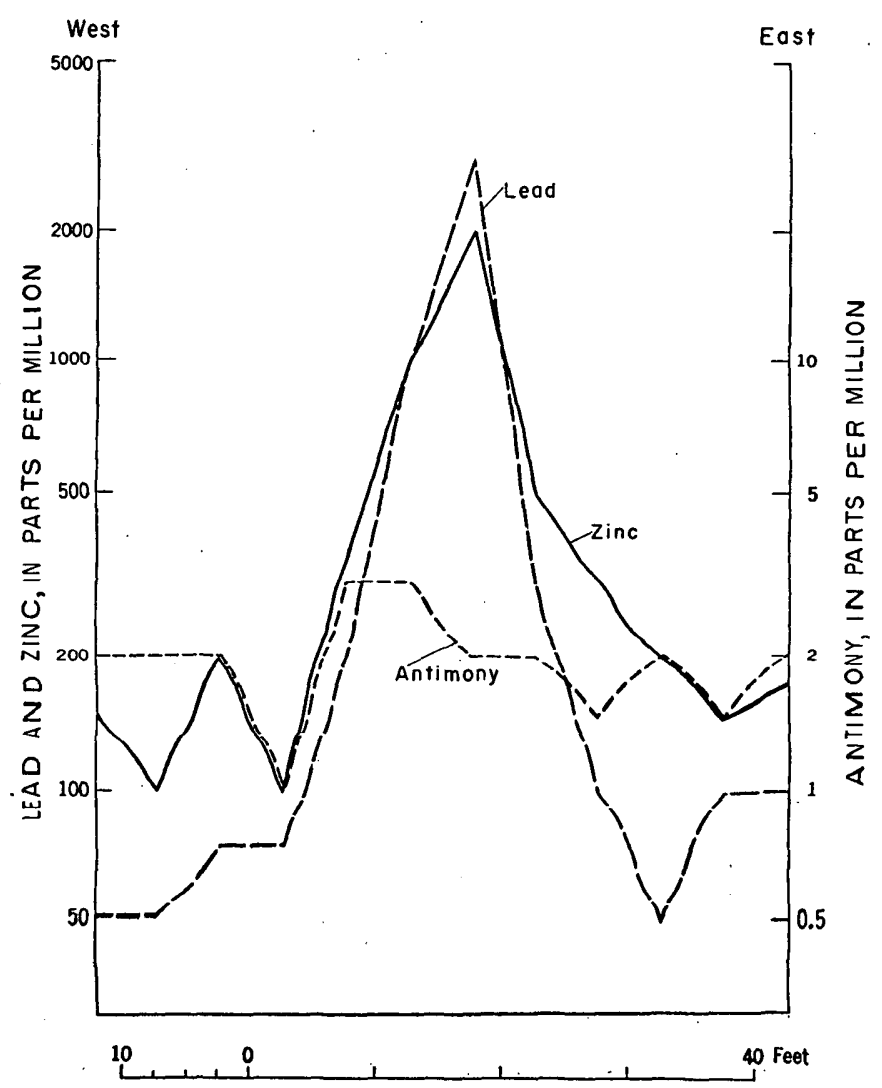

Figure 10.-Metal content of alluvium over Ameri lode. 
bution of lead, zinc, and antimony in these samples. By analogy with the relationships found in the trench, it may be assumed that the position of the subout crop of the vein coincides with the peaks on the curves for lead and zinc. Copper, cobalt, nickel, silver, and arsenic were also determined in these samples, but showed little or no correlation with the pattern for lead and zinc or with the probable location of the lode.

The sample holes were made with a standard soil auger. A satisfactory soil auger may be built by brazing or welding a standard woodauger bit to a section of light cast-iron pipe, to the top of which is fitted a cross piece to serve as a handle. If necessary, additional sections of pipe may be attached for greater depth. One African assistant was able to collect 12 samples from a depth of four feet in a 6-hour working day. At the time of the experiment, the clay was fairly dry and hard; with moist, pliable clay; it is probable that a somewhat better rate could be achieved.

As a result of the experimental work in the Ameri swamp, the following conclusions are offered regarding the behavior of lead and zinc in alluvial clays:

(1) Zinc and, to a lesser extent, lead move up into alluvial cover from suboutcrops of sulfide-bearing lodes.

(2) Subsurface samples at a spacing not greater than the width of the lode will under favorable conditions show a pattern of zinc and lead that can be used in locating buried lead-zinc lodes. Surface samples at 50-foot spacing, as used in reconnaissance on residual, lateritic cover, are not adequate for locating lodes under alluvial cover.

(3) Clay cover can be identified as alluvial rather than residual in origin if a sharp basal contact with the underlying rock can be observed, and if the clay contains obviously exotic fragments. Otherwise, alluvial clay cannot be positively distinguished from residual clay by any method known to the writer.

\section{DISTRIBUTION IN ROCKS ADJOINING VEINS}

Natural exposures of unweathered shale are seen only in deep river channels, which are lacking in the immediate vicinity of the mines of the Nyeba district. It was therefore not possible to get samples for the determination of the background metal content of completely unweathered shale known to be unmineralized. The average metal content of the two samples of partially weathered shale from areas believed to be unmineralized is $67 \mathrm{ppm} \mathrm{Pb}$ and $160 \mathrm{ppm} \mathrm{Zn}$, as determined by quantitative colorimetric analysis. It must be remembered that, because of the relative mobility of zinc in the weathering cycle compared to that of lead, these samples of weathered shale may be somewhat lower in zinc and higher in lead than the parent shale. 
The lead content of residual soils in the area of the Palm Wine lode is substantially higher than normal. In the area covered by figure 5 , the average lead content of the 156 samples taken south of the claycovered swamp and outside the anomalous area over the lode, is 475 ppm $\mathrm{Pb}$, as compared with a background for soil of between 30 and $50 \mathrm{ppm}$. The average zinc content of the same samples is $65 \mathrm{ppm}$, or essentially the normal background content for lateritic soils. North. of the clay-covered swamp, the lead content is not substantially above background. Inasmuch as the surface of the ground south of the swamp slopes fairly uniformly to the northwest, it is extremely unlikely that very much of the excessive lead in the residual soils was derived by erosion of lead-rich material from the main lode. Contamination of such an extensive area by human activities seems equally unlikely. The possibility remains, therefore, that the lead-rich residual soils reflect a higher than normal lead content of the parent shales.

To determine the relation of the metal content of soils to that of the unweathered bedrock in the vicinity of the Palm Wine lode, samples taken of the core from bore hole 1 (fig. 5) were made available to the writer by the mining company. Each sample represents a split of the contents of the core barrel each time the drilling tools were withdrawn from the hole. The samples were digested in nitric and hydrofluoric acids, and the lead and zinc content of each sample estimated by the rapid dithizone procedure; in addition, weighted composite samples were prepared and analyzed by quantitative colorimetric methods. Table 8 shows the analytical results.

For the section west of the ore zone, the quantitative value for lead on the weighted composite sample is $185 \mathrm{ppm}$, which is significantly above background but not nearly as high as the $475 \mathrm{ppm}$ average $\mathrm{Pb}$ content of the residual soils. For the section east of the ore zone, the lead content is $66 \mathrm{ppm}$, which is not substantially different from. the assumed background for unmineralized shale. The zinc content of both sections is well above the assumed zinc background, and contrasts sharply with the relatively low zinc content of the soils. The bore hole samples are, of course, a very inadequate representation of the rocks of the area, a fact that may account for some of the discrepancy between the rock and soil data. Part of the discrepancy may also be the effect of the demonstrated tendency for lead to be enriched and for zinc to be impoverished in the course of weathering.

In conclusion, the drill core data do not wholly support the idea that the abnormally high lead content of soils in the vicinity of the Palm Wine lode is a reflection of a primary dispersion of lead in the shale bed rock; nevertheless; in the absence of evidence to the contrary, the existence of a primary anomaly in this area seems to be the most reasonable working hypothesis. 
Table 8.-Distribution of lead and zinc in Palm Wine bore hole 1.

(Detailed Log)

\begin{tabular}{|c|c|c|c|c|c|c|c|}
\hline \multicolumn{2}{|c|}{ Depth (feet) } & \multirow{2}{*}{$\begin{array}{l}\text { Feet of } \\
\text { core }\end{array}$} & \multicolumn{2}{|c|}{ Parts per million } & \multirow{2}{*}{\multicolumn{3}{|c|}{ Description }} \\
\hline From & To & & Lead & Zinc & & & \\
\hline 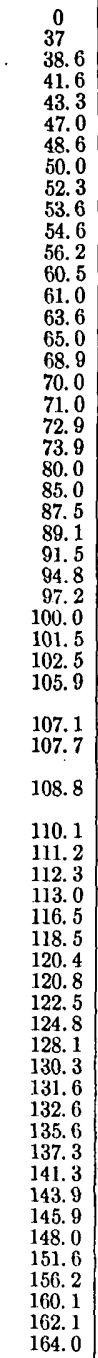 & $\begin{array}{r}37 \\
38.6 \\
41.6 \\
43.3 \\
47.0 \\
48.6 \\
50.0 \\
52.3 \\
53.6 \\
54.6 \\
56.2 \\
60.5 \\
61.0 \\
63.6 \\
65.0 \\
68.9 \\
70.0 \\
71.0 \\
72.9 \\
73.9 \\
80.0 \\
85.0 \\
87.5 \\
89.1 \\
91.5 \\
94.8 \\
97.2 \\
100.0 \\
101.5 \\
102.5 \\
105.9 \\
107.1 \\
107.7 \\
108.8\end{array}$ & $\begin{array}{l}37.0 \\
1.6 \\
3.0 \\
1.7 \\
3.7 \\
1.6 \\
1.4 \\
2.3 \\
1.3 \\
1.0 \\
1.6 \\
4.3 \\
0.5 \\
2.6 \\
1.4 \\
3.9 \\
1.1 \\
1.0 \\
1.9 \\
1.0 \\
6.1 \\
5.0 \\
2.5 \\
1.6 \\
2.4 \\
3.3 \\
2.4 \\
2.8 \\
1.5 \\
1.0 \\
3.4 \\
1.2 \\
0.6 \\
1.1\end{array}$ & 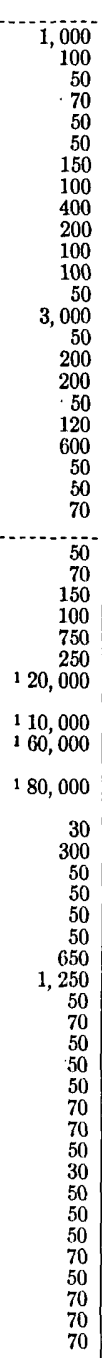 & 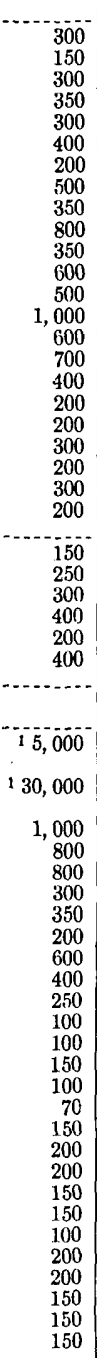 & \multicolumn{3}{|c|}{$\begin{array}{l}\text { Noncoring. } \\
\text { Intercalated shale and sandstone. } \\
\text { Do. } \\
\text { Do. } \\
\text { Do. } \\
\text { Do. } \\
\text { Do. } \\
\text { Do. } \\
\text { Do. } \\
\text { Barren siderite with sparse marcasite. } \\
\text { Intercalated shale and sandstone. } \\
\text { Do. } \\
\text { Do. } \\
\text { Do. } \\
\text { Do. } \\
\text { Do. } \\
\text { Do. } \\
\text { Do. } \\
\text { Do. } \\
\text { Do. } \\
\text { Do. } \\
\text { Do. } \\
\text { Do. } \\
\text { Do. } \\
\text { No core. } \\
\text { Intercalated shale and sandstone. } \\
\text { Do. } \\
\text { Do. } \\
\text { Do. } \\
\text { Do. } \\
\text { Marcasite and siderite at end of run. } \\
\text { Barren siderite and marcasite with few spots of } \\
\text { galena. } \\
\text { Do. } \\
\text { Siderite and marcasite with some galena and sparse }\end{array}$} \\
\hline & & \multicolumn{6}{|c|}{ Summary } \\
\hline & & \multicolumn{4}{|c|}{$\begin{array}{l}\text { Weighted averages of data from detailed } \\
\qquad \log \end{array}$} & \multicolumn{2}{|c|}{$\begin{array}{l}\text { Quantitative de- } \\
\text { terminations on } \\
\text { weighted compos- } \\
\text { ite samples }\end{array}$} \\
\hline & & \multicolumn{2}{|c|}{ Depth (feet) } & \multicolumn{2}{|c|}{ Parts per million } & Parts pe & million \\
\hline & & From & To & Lead & Zine & Lead & Zinc \\
\hline & 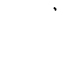 & $\begin{array}{r}37.0 \\
112.3\end{array}$ & $\begin{array}{l}102.5 \\
166.9\end{array}$ & $\begin{array}{r}239 \\
97\end{array}$ & $\begin{array}{l}335 \\
193\end{array}$ & $\begin{array}{r}185 \\
66\end{array}$ & $\begin{array}{l}380 \\
178\end{array}$ \\
\hline
\end{tabular}

1 A ssay values for lead and zinc furnished by $\mathrm{N}$ igerian Lead-Zinc Mining Company. 


\section{VEGETATION}

The present series of experiments did not include geochemical exploration by collection and analysis of vegetation. Webb and Millman (1951) carried out a fairly extensive investigation on the lead, zinc, and silver content in vegetation as a guide to ore in the Nyeba district, and the reader is referred to their report for details. Their conclusions are quoted below in full (Webb and Millman, 1951, p. 499) :

Marked increases in the conceutrations of lead and zinc in plants can be correlated with proximity to lead-zinc vein deposits. Using a spectrographic analytical technique, lead is found to be the more satisfactory index element. In addition, silver has a limited value as a "pathfinder" element.

The anomalies, which in places attain widths of several hundred feet, are considerably wider than the responsible mineralized zones. Several interrelated factors contribute to the nature, width and magnitude of the observed anomalies over known mineralizations. In addition to certain botanical considerations, these factors include (a) width and tenor of the mineralization near the surface, (b) the mineralogy and degree of oxidation of the ore, (c) mobility of the metals in the zone of weathering, (d) topographic relief, (e) disturbance by mining, and probably other factors. Their relative importance is peculiar to each locality.

In the area examined, several species of trees of the savannah vegetation possessing a convenient collective distribution provide suitable sampling points. The data are incomplete, but apart from minor parochial and specific variations, all the species examined seem to behave as normal accumulator plants towards lead, zinc, and silver. Although the background concentrations of these metals are usually rather higher in leaves than in twigs, both parts of the plant give comparable anomalies over mineralization. Twig samples are found to be more convenient in practice and, subject to the results of control work, it seems probable that anomalies would be detectable in twigs at most times of the year.

Much of the work was carried out in areas where the lodes have been disturbed, mainly by shallow opencasting. A smaller number of analyses indicate that appreciable anomalies are also detectable over essentially virgin, sub-outcropping veins. The results suggest that, in favourable circumstances, a hidden economic lode could be expected to promote increased metal concentrations in suitable plants for some appreciable distance on either side of its sub-outcrop. Fluctuations in the biogeochemical profiles due to botanical and other factors, not directly related to mineralization, should not in general obscure an anomaly associated with an economic deposit. However, although such fluctuations are usually relatively small, occasional higher values may have a deceptive significance.

It is considered that the systematic determination of the metal concentrations in plants shows promise of providing a useful supplementary aid to mineral exploration in the Nigerian lead-zinc belt and in other areas where similar favourable conditions prevail.

From the practical point of view, further orientation studies might be undertaken, combined with the investigation of other analytical techniques and a comparison of the relative advantages and requirements of the plant and soil methods of geochemical prospecting. In addition, there is a wide field for research in the basic principles and processes involved.

The writer collected soil samples along Traverse $A-B$, across the southerly projection of the Ameka lode, as shown in Webb and Millman's plate 3 (fig. 2 of this report for location). These samples all 


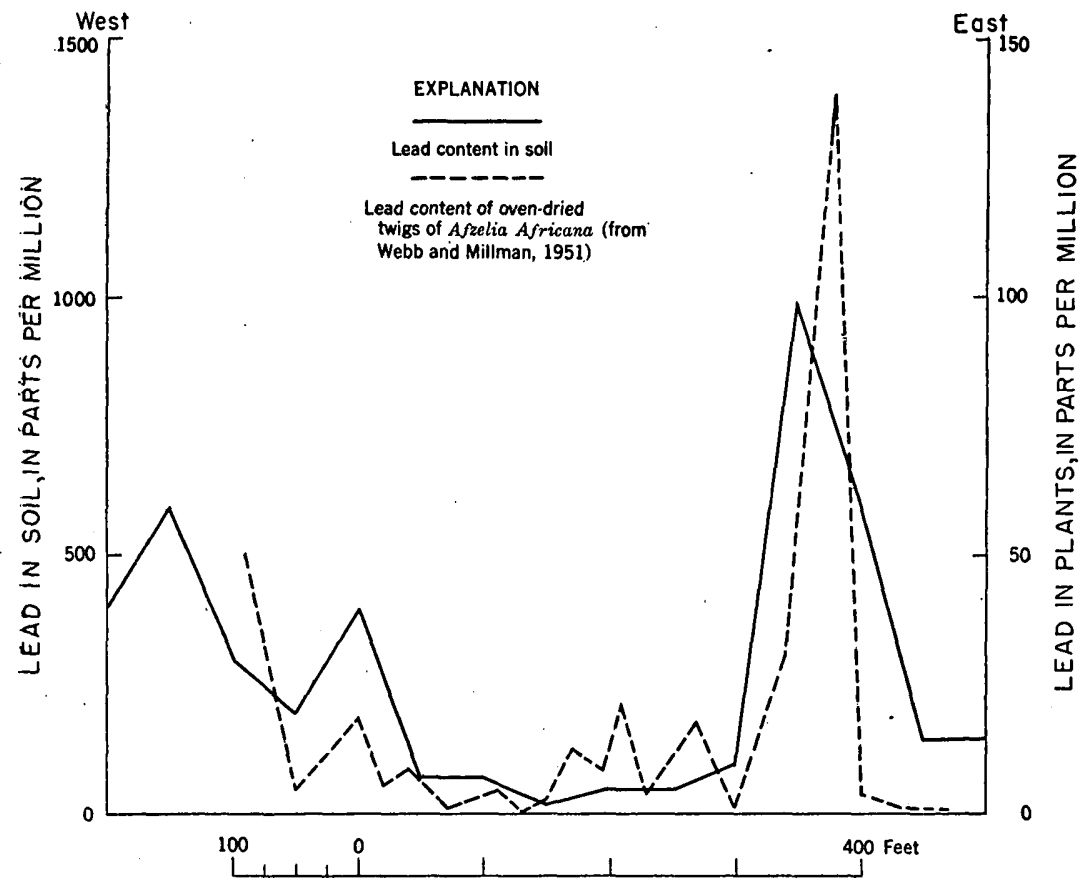

Fiodri 11:-Comparative lead content of solls and plants near Ameka lode.

consisted of residual lateritic soil, and were well outside the area of disturbance caused by mining activity around the Ameka lode. Figure 11 shows the comparative lead content of soils and plants along this traverse. These soils were also analyzed for zinc, silver, copper, cobalt, nickel, arsenic, and antimony. The correlation between the zinc content of plants as determined by Webb and Millman and the zinc content of the corresponding soils is not as well marked as that of lead. The silver content of all the soils was below the $0.2 \mathrm{ppm}$ sensitivity of the analytical procedure, so that no comparison was possible for silver. The other elements either showed no systematic correlation with the lead, zinc, and silver content of the plants (copper, cobalt, antimony) or were present in amounts below the sensitivity of the analytical method (nickel, arsenic). This fragmentary bit of information indicates that, at least for lead, the pattern of distribution in the plant species sampled by Webb and Millman is similar to that in the supporting soils.

It would be premature to hazard a guess as to the relative economics of geochemical plant surveys as against soil surveys until cost data for the plant work could be worked out on a basis strictly comparable with that of the soil survey. The majority of workers familiar with both methods of approach are generally of the opinion that soil work is more economical where it is applicable, and that plant sampling should be saved for problems where for some reason the study of soils 
fails to provide the desired information. However, the relative economy and effectiveness of the two methods is a question still actively being debated, and the final answer must await further research.

\section{WATER}

Webb and Millman (1950) in summarizing their experimental work on geochemical water surveying in the Nyeba district, conclude that springs issuing from the lodes contained relatirely high concentrations of heavy metals (undifferentiated zinc, copper, and lead). The addition of these natural lode waters to the main drainage system caused significant increases in the metal content of the stream waters, the magnitude of these increments being subject to considerable diurnal variation during the rainy season.

Many of the samples reported by Webb and Millman were from springs or surface water in the vicinity of the Ameka lode, which has been extensively excavated and exposed to accelerated oxidation and solution by ground water passing through the old workings.

Webb and Millman also sampled surface water in the vicinity of the Ameri No. 2 lode, now known as the Ikwo ( $\overline{\mathrm{E}}^{\prime} \mathrm{kwo}$ ) lode (fig. 2), where increments of metal from oxidizing sulfide minerals in oId mine workings are probably negligible. Their results follow:

\begin{tabular}{|c|c|}
\hline Sampling point. & $\begin{array}{c}\text { Heavy metals: } \\
\text { (ppm) }\end{array}$ \\
\hline $\begin{array}{l}275 \mathrm{ft} \text { upstream from lode } \\
125 \mathrm{ft} \text { upstream from lode } \\
\text { Juju pool at lode (overflow joins the stream) } \\
\text { 500 ft downstream from lode }\end{array}$ & $\begin{array}{r}0.05 \\
.05 \\
.5 \\
.1\end{array}$ \\
\hline
\end{tabular}

In an effort to reconfirm and extend the earlier work of Webb and Millman, the writer attempted to analyze similar samples of surface water by the same method (Huff, 1948). With almost all of the water samples collected, however, the dithizone solution oxidized rapidly to a dirty-green or yellow color, and with many of the samples the carbon tetrachloride emulsified on shaking so that no clean, two-phase separation was obtained. After some experimental work on the procedure, the water sampling program was abandoned.

Interferences of this kind have been commonly attributed to organic impurities in the water. The difference in the response of the same test in the hands of different workers probably lies in the season of the year when the samples were collected. Webb and Millman collected their samples during the rainy season when presumably tho content of organic refuse in the water was not high enough to cause interferences, whereas the author's samples were taken at the beginning of the dry season when streams and pools were stagnant and highly charged with putrifying organic matter. 


\section{EXPERIMENTAL GEOCHEMICAL SOIL SURVEYS}

With the exception of the Ameri lode, every known lode in the Nyeba district gave some surface evidence for its existence in the form of fragments of limonite, sulfate-coated galena, or quartz in the surface rubble and the material of the yam heaps. As has already been pointed out in connection with the soil erosion problem, it is quite likely that all the veins of any importance in the district in areas of lateritic weathering have already been discovered; as a result of the very thorough and intensive scouting for this type of evidence by African prospectors in the employ of the mining companies. In the well-drained parts of the Nyeba district, therefore, conventional methods of prospecting appear to be quite adequate, and geochemical prospecting methods are hardly needed, even though they can be shown to be outstandingly effective. The experimental soil sampling surveys described below were carried out more for the purpose of determining the economics of geochemical work manned principally by African labor than of making any new mineral discoveries. There is good reason to believe that the cost and probably the effectiveness of geochemical soil surveying in the tropics would not be substantially different in areas of deeper soil cover, where conventional methods of prospecting would be of little or no value.

\section{SAIMPLING METHODS}

As a result of the field experiments already discussed, it was concluded that samples of soil collected at a depth of 6 inches and at 100foot intervals were most suitable for reconnaissance work. Although samples of 100-foot intervals would have been quite adequate to locate all the major anomalies, a 50-foot sample interval was used in the experimental surveys for the sake of gathering additional confirmatory data on the optimum spacing. An all-African field crew of eight men was trained for this work. Surveying and sampling equipment included a prismatic compass mounted on a tripod, a 100-foot link chain, a survey pole, and machetes for cutting brush and digging holes. The crew consisted of a party chief, a compass man, two men on the chain, one lead man with the survey pole as a foresight target, one man to dig the sample holes, and two men to cut survey lines. Sample holes were prepared by chopping and cleaning out a hole 6 inches deep with the end of a machete, and loosening a handful of earth from the bottom of the hole which was left in place to dry. Samples were collected a day or two later, after they had dried sufficiently to be sieved. Sieving was done at the sample site with an 80-mesh stainless-steel sieve, the +80 mesh fraction discarded, and about 3 grams of the fines retained for analysis. Samples were collected in 3 - by 5 - inch manila envelopes sealed with fold-down metal tabs. Sample numbers, which were written on the outside of the 
envelope, were assigned in the order of collection, regardless of the type of material sampled or the nature of the problem. Description and location of the samples were entered in the notebook.

On this basis, the African crew averaged 1,500 feet of traverse, or 30 samples, per 6-hour working day. Much of this time was taken up with cutting brush; in open country, the crew could average 3,000 to 4,000 feet (60 to 80 samples) per day. The principal factor governing the productivity of the crew appeared to be the length of traverse and the amount of brush to be cut, rather than the number of samples. The party chief for the job was a member of the permanent junior staff of the Nigerian Geological Survey Department, who was given complete responsibility for all aspects of routine sampling work. The only participation by Europeans in the sampling program was in laying out the problem and in studying the geology or surface features of the terrain after the lines had been cut and the: samples collected.

All of the soil sampling was done in the dry season, when the loosened earth in the sample holes was dry enough for sieving in the field after exposure to the air of a day or two. In the rainy season, it would be necessary to collect the samples wet, and dry them later in an oven before sieving. An added difficulty with moist samples is that the glue in standard containers or envelopes will soften so that many samples will be lost in transit, and all samples must be repackaged when dry. Sample containers made with waterproof glue have been put on the market, but the writer has had little experience with them. Another alternative is to wrap the wet sample in waterproof paper or metal foil before inserting it in the envelope. Because of the difficulties in handling wet samples, it would, in general, be best to avoid the problem completely by planning the program so that all soil sampling can be done in the dry season.

An unanticipated difficulty was the destruction of sample envelopes. by white ants. A large part of the supply of envelopes in the mining company's laboratory at Nyeba were thus destroyed during 6 months. of storage.

\section{APPRAISAL OF PROSPECTS BY GEOCHEMICAL METHODS}

R. G. Bogue in the course of his geological investigations found scattered fragments of gossan and the remains of an ancient opencast pit at a point about 3 miles north of the Igbaja dispensary, and about 30 miles north of Nyeba (fig. 1). He suggested that geochemical methods be used for appraisal of the prospect and for determination of the size and continuity of the bedrock deposit, if any existed.

Four parallel sample traverses were laid out, one across the ancient workings, one to the south, and two to the north of them, as shown on: figure 12. The traverse across the old workings shows a very definite. 


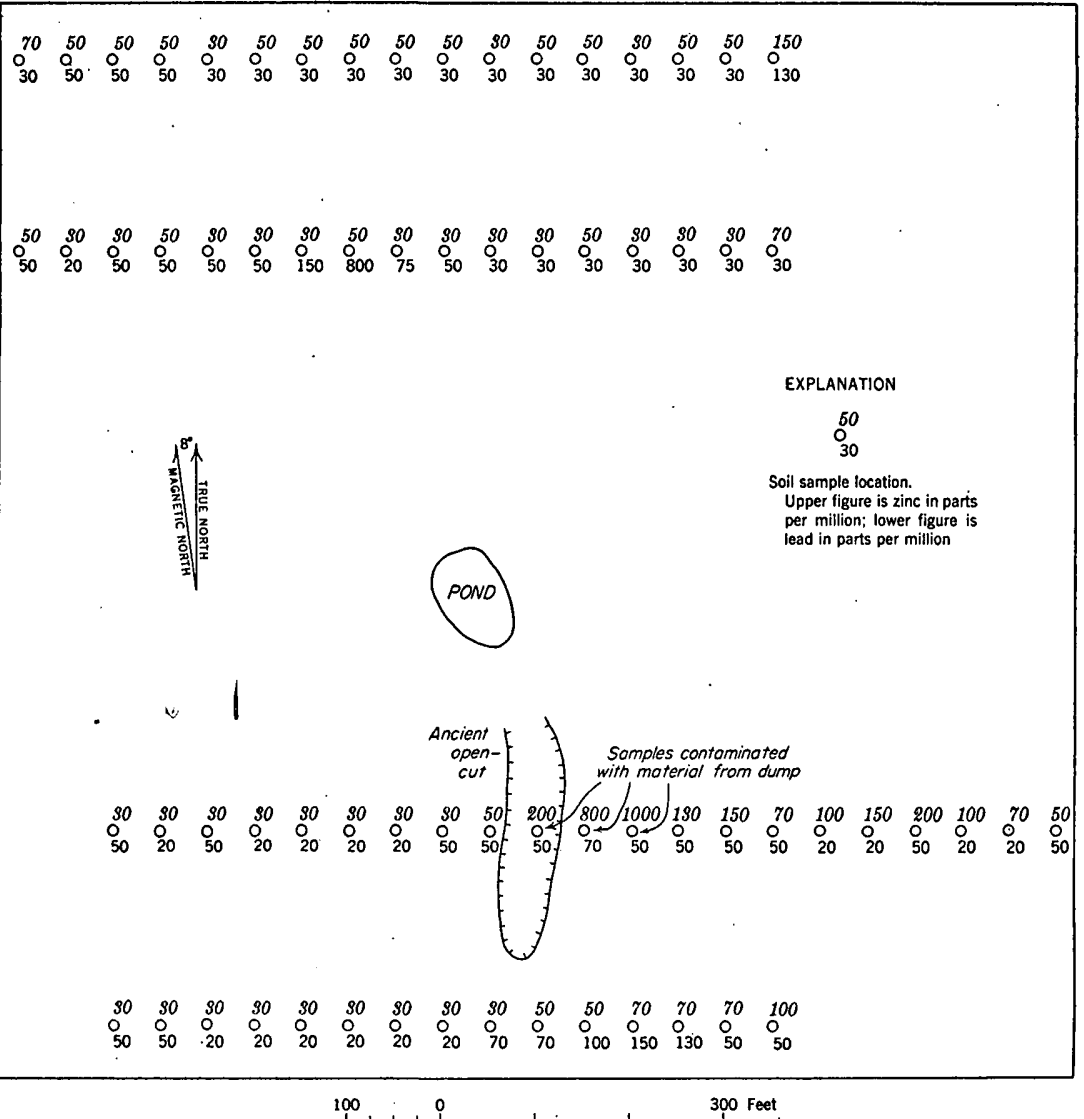

Figure 12.-Geochemical soll survey, Igbaja prospect.

geochemical anomaly in zinc, although the pattern may have been somewhat disturbed by contamination from the old workings. Theother traverses show no outstanding pattern in zinc, although there are variations in the lead content that may indicate minor sulfides in the bedrock. No strong pattern of lead and zinc distribution similarto that found at the Palm Wine lode is apparent, and it may be safely concluded that the chances of an important sulfide deposit at this. locality are slight.

Sample collection required one day of field work on the part of the African sampling crew, and one day of analytical work in the local laboratory. As a result, it was possible in two days to eliminate. this occurrence as a likely prospect with considerable certainty.

\section{RECONNAISSANCE EXPLORATION}

An experimental geochemical reconnaissance survey of the area between the Ameri and Palm Wine lodes was conducted for the purpose of gaining experience with a large-scale surveying and sampling: 


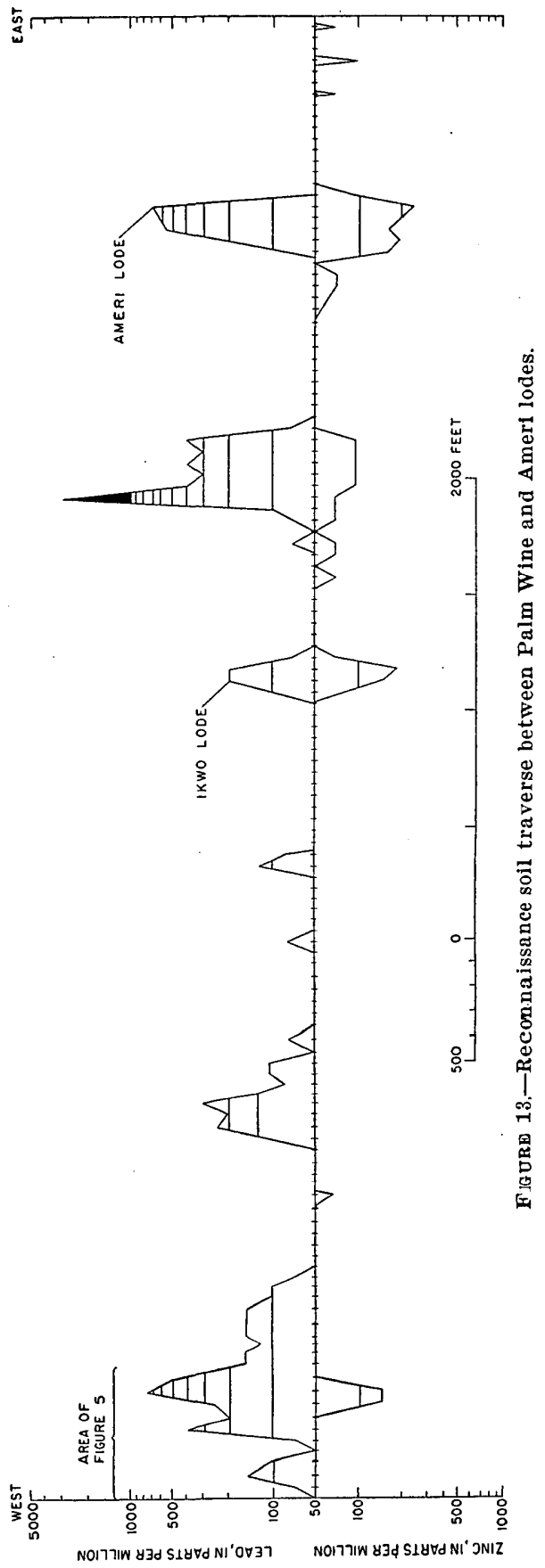


program entrusted entirely to African labor. The work was laid out as a series of parallel east-west sample traverses, along which soil samples were collected at 50-foot intervals. Figure 2 shows the location of sample traverses. Through an unfortunate accident, most of these samples were destroyed; the data from those that were saved, however, are shown on figure 13. On this traverse, it is interesting to. note that the Ameri and Ikwo lodes as well as the area of lead-rich soils adjoining the Palm Wine lode are all indicated prominently in the geochemical curves. In addition, two unexplained geochemical anomalies were brought to light by the data from this traverse.

\section{CONCLUSTONS}

The following conclusions are believed to be accurate for the Nyeba: district, and are probably valid for many other areas in the tropics:

1. The lead and zinc content of 3-gram samples of the minus 80 . mesh fraction of lateritic residual soil collected at a depth of 6 inches. and a spacing of 50 feet may be depended on with confidence to indicate the presence of lead-zinc veins in the bedrock in the immediate vicinity. Samples collected at 100 -foot intervals would be adequate to locate the Palm Wine and Ameri lodes. Significant anomaly values: are 100 to $200 \mathrm{ppm}$ for zinc and commonly 500 to $1,000 \mathrm{ppm}$ for lead, over a background of $50 \mathrm{ppm}$ for zinc and $30 \mathrm{ppm}$ for lead.

2. Sampling and analysis of residual clay soils at similar depth and spacing will probably serve to locate veins in the immediate vicinity.

3. The lead and zinc content of samples of recent alluvial clay deposits taken from two to three feet above the surface of bedrock, at a spacing not greater than the width of the lode, will under some conditions show the location of suboutcrops of lodes containing galena and sphalerite.

4. The lead and zinc content of limonitic gossan may provide evidence for base-metal mineralization where the primary sulfides have been completely oxidized.

5. African labor can be trained to do all but a minor part of the routine work of sample collection and analysis.

\section{UNSOLVED PROBLEMS}

It seems to be true of almost every investigation in a new field that more problems are brought to light in the course of the work than are solved. Among the most important unanswered questions raised by the present work in Nigeria are the following:

1. Would the geochemical halos of lead and zinc determined by sampling near-surface soils be as well-developed if soil erosion had not removed the indigenous weathering profile in the Nyeba district? 
2. Can reliable and simple criteria be worked out for distinguishing residual from alluvial clay cover?

3. What is the mechanism whereby zinc and lead migrate upward into transported cover from veins in the underlying bedrock?

4. Can a test for metals in water be developed that is suitable for all natural water regardless of organic contamination?

5. How does the cost of geochemical soil work compare with plant work as a method of geochemical reconnaissance exploration?

\section{REFERENCES CITED}

Almond, Hy, 1953, Determination of traces of cobalt in soils: Analytical Chemistry, v. 25, p. 166-167.

Almond, Hy, and Morris, H. T., 1951, Geochemical techniques as applied in recent investigations in the Tintic district, Utah: Econ. Geology, v. 46, p. 608-625.

Cooper, J. R., and Huff, L. C., 1951, Geological investigations and geochemical prospecting experiment at Johnson, Arizona: Econ. Geology, v. 46, p. 731-756.

.du Preez, J. W., 1948, Laterite : a general discussion with a description of Nigerian occurrences: Bull. Agricole du Congo Belge, v. 40, p. 53-66.

Elkins, H. B., 1950, The chemistry of industrial toxicology : John Wiley and Sons, New York, $406 \mathrm{p}$.

Farrington, J. L., 1952, preliminary description of the Nigerian lead-zinc field: Econ. Geology, v. 47, p. 583-608.

Fersman, A. Ye, 1939, Geokhimicheskiye i minerologicheskiye metody poiskov poleznykh iskopayemykh [Geochemical and mineralogical methods of prospecting for mineral deposits] : Akad. Nauk SSSR, Moscow. (English translation of Chap. IV, Special methods of prospecting, by Lydia Hartsock and A. P. Pierce, released as U. S. Geol. Survey Circular 127, 37 p., 1952.)

Guillemain, 1910, Die Eisenindustrie der Eingeborenen Kameruns: Koloniale Rundschau, Jahrg. 1910, no. 1, p. 15-25.

Harbaugh, J. W., 1953, Geochemical prospecting abstracts through June 1952: U. S. Geol. Survey Bull. 1000-A, p. 1-50.

Hawkes, H. E., 1948, Annotated bibliography of papers on geochemical prospecting for ores: U. S. Geol. Survey Circular 28, 6 p.

1950, Geochemical prospecting for ores, in Trask, P. D., Applied sedimentation, John Wiley and Sons, New York, p. 537-555.

1952, What geochemistry is and what it can do: Min. Cong. Jour., v. 37, no. 9 , p. 55-58.

'Huff, L. C., 1948, A sensitive' field test for heavy metals in water : Econ. Geology, v. 43 , p. $675-684$.

Lakin, H. W., Almond, Hy; and Ward, F. N., 1952, Compilation of field methods used in geochemical prospecting by the U. S. Geological Survey: U. S. Geol. Survey Circular 161, $34 \mathrm{p}$.

Lakin, H. W., Stevens, R. E., and Almond, Hy, 1949, Field method for the determination of zinc in soils : Econ. Geology, v. 44, p. 296-306.

Lovering, T. S., Sokoloff, V. P., and Morris, H. T., 1948, Heavy metals in altered rock over blind ore bodies, East Tintic district, Utah: Econ. Geology, v. 43, p. 384-399.

Mackay, R. A., 1950, The lead and zinc veins in the Lower Cretaceous of Nigeria : Proc. Int. Geol. Cong. (XVIII Session), Pt. VI, p. 217-220.

Minerals Yearbook, 1949, U. S. Bureau of Mines, p. 483, 1212, 1292. 
Morris, H. T., 1952, Supergene and hydrothermal dispersion of heavy metals in wall rocks near ore bodies, Tintic district, Utah. Part II, Primary dispersion patterns of heavy metals in carbonate and quartz monzonite wall rocks : Econ. Geology, v. 47, p. 698-716.

Rankama, K. K., 1947, Some recent trends in prospecting: chemical, biogeochemical, and geobotanical methods: Mining and Metallurgy, v. 28, p. 282-284.

Riddell, J. E., 1950, A technique for the determination of traces of epigenetic base metals in rocks : Quebec Dept. Mines, Prel. Rept. 239.

Roberts, R. O., 1953, Geochemical investigation in Nigeria in 1948 and 1949; Colonial Geol. and Min. Res., v. 3, No. 4, p. 347-357.

Sandell, E. B., 1950, Colorimetric determination of traces of metals : $2 d$ ed., 673 p., New York, Interscience Publishers, Inc.

:Sergejev, Ye. A., 1941, Fiziko-khimcheskiy metod poiskov rudnykh zalezhey [Geochemical method of prospecting for ore deposits] Materialy Vses. Nauchno-Issled. Geol. Inst., Geofizilka, sbornik 9-10, p. 3-55, (English translation by V. P. Solkoloff in Selected Russian papers on geochemical prospecting for ores. Released for free distribution by the U. S. Geological Survey, February 1950).

Tattam, C. M., 1930, The lead-zinc deposits of Ogoja Province: Geol. Survey Nigeria Ann. Rept., p. 14-23.

- 1943, A review of Nigerian stratigraphy: Geol. Survey Nigeria Ann. Rept., p. 27-40.

Webb, J. S., and Millman, A. P., 1950, Heavy metals in natural waters as a guide to ore; a preliminary investigation in West Africa : Inst. Min. Metallurgy Bull. 518, p. 3-16.

1951, Heavy metals in vegetation as a guide to ore: Inst. Min. MetalIurgy, Trans. v. 60, pt. 2, p. 473-504. 



\section{INDEX}

\begin{abstract}
Acknowledgments for aid

Agricultural practices

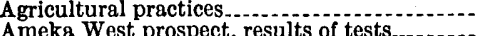

Analytic methods, requirements

Anomalies, primary, Palm Wine prices, primary, at Palm primary in overlying rock. occurrence of metals in . . . . "wall rock" halos

secondary, superimposed halos vegetation.

signiflcant values. width.

Antimony, distribution

Background

Biogeochemical anomalies. See Plant anomalies.
\end{abstract}

Bogue, R. G., and Reynolds, R. R., quoted.. 58-61

Catastrophic cycle of soil erosion

$65,87,88$

(1)

Colorimetric tests. . . .

Contamination, effect on geochemical investigations.

sources gations

Copper, distribution.

Crew

Crocodile prospect, resuits of tests.

Determinations, accuracy

comparison of fleld with Denver Labora.

total and average number

Earlier geochemical investigations.

Enrichment, systematic during weathering...

Field work

Galena, resistance to oxidation

Geochemical prospecting, defined

Geologic mapping, handicaps

Geology

Gossan.

Igbaja prospect, survey at

Igneous rocks

Iron industry, ancient

Juju pools

Laboratory fleld

Laterite.

Lead compared to diffored to zinc in vegetation analysis estimation of

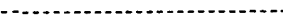

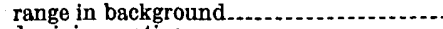

Lead mining, native.

Limonite.

Mineralogy

Mobility of elements

60-6:

Nickel

96-97

61,62 $\begin{array}{cr}\text { Page } & \begin{array}{r}\text { Pag } \\ 59\end{array} \\ \text { occurrence }\end{array}$ wall rock alteration....... $59-60$

Palm Wine lode

Plant anomalies. 90

Plant anomalies........- 55

Poorly drained areas, possibilitios of mew Poorly drained areas, possibilities or new discoveries........................

Primary minerals .......... identification in gossan . . Purpose of investigation.

Reagents. $68,70,71$

Reconnaissance survey, experimental...... $97-99$

Relative solubility of metals

Residual soils, lead content, Palm Wine lode.- $\quad 90$

Samples, alluvium ............ 87

bore hole......... 90

digestion of

gossan

methods of collecting

rate of taking

shipment of

slag - . . .

spacing of

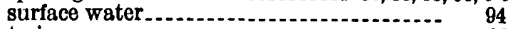

twig

unmineralized rock

Seasons.................... 62, 94, 96

Sedimentary rocks

Shale, unwesthered, outcrops of

Silicified wall rock, protection of lodes by....

Silver, distribution.............................. 92,93

Soil, alluvial................. 85-87

clay . . 64

content of lead and zinc contrasted...... 78

fragmental zone............................ 62

importance in investigations......

laterite..................... 63

Soil and plant surveys, costs compared..... 93-94

Soil auger, use in sampling

Surficial factors, importance in mineral investi-

gations............. 61

Systematic distribution of elements, lacking in siliceous schists........ 77

lack of some at Ameri lode 89

in-vertical profles, Ameri lode....... 87-88

in weatheredklateritic rocks_.

Threshold . . .

Topography.......... 61

Vegetation ................ 64 geochemical exploration by analysis of...

Weathered bedrock............ 63,64

Weathering profles, in poorly drained areas. $63-64$

in well-drained areas.................. 62-63

Webb, J. B. and Millman, A. P., quoted 58, 92-94

Well-drained areas, doubtful possibility of new discoveries... 65, 95

Zinc, estimation of . 71 lower values in rapid determinations.... 74 range in background removal from solution :threshold'at A meri lodè: ............ 80 